\title{
Multispecies probiotics promote perceived human health and wellbeing: insights into the value of retrospective studies on user experiences
}

\author{
A.M. van der Geest ${ }^{1}$, I. Besseling-van der Vaart ${ }^{2}$, E.M. Schellinger-de Goede ${ }^{2}$, M.B. van der Waal ${ }^{1}$, E. Claassen ${ }^{1}$, \\ J. Flach ${ }^{1,3}$ and L.H.M. van de Burgwal ${ }^{1}$ \\ ${ }^{1}$ Vrije Universiteit Amsterdam, Athena Institute, De Boelelaan 1085, 1081 HV Amsterdam, the Netherlands; ${ }^{2}$ Winclove \\ Probiotics BV, Hulstweg 11, 1032 LB Amsterdam, the Netherlands; ${ }^{3}$ CR2O BV, Bisonspoor 3002-C701, 3605 LT Maarssen, \\ the Netherlands; a.m.vander.geest@vu.nl
}

Received: 11 August 2020 / Accepted: 12 January 2021

(c) 2021 Wageningen Academic Publishers

\section{OPEN ACCESS (c) RE(-) RESERCH ARTICLE}

\begin{abstract}
When taking a broader perspective on the societal impact of probiotics, engagement of end-users is important to discover unmet needs, define relevant health benefits and identify key considerations for successful implementation in daily practice. This study therefore takes a retrospective approach and analyses a database of user experiences to review the effects of four multispecies probiotic formulations. The user experiences were analysed in a dependent sample manner (without control group) and complement previous randomised controlled trials that have been performed with the formulations. The database consisted of 584 evaluable user experiences regarding the impact of probiotic supplementation on perceived quality of life (QoL), gastrointestinal (GIT) symptoms and reported stool consistency after two weeks of consumption. Two different scales were used ( $\mathrm{n}=344$ in a 5 -point scale; $\mathrm{n}=240$ in a 10-point scale), which are presented as separate analyses. In the combined population of the 5-point-scale questionnaire, a significant increase in perceived QoL and a significant reduction in perceived GIT symptoms was observed. Descriptive summaries also indicate that diarrhoea- and constipation-like stool patterns are reduced following supplementation. Moreover, half of participants indicated that probiotic supplementation had a positive effect on their unmet medical need, and $64 \%$ of users were likely to continue using the product. Similar results were observed in the 10-point scale questionnaire. Considering the clinical relevance of probiotic supplementation in specific target groups, subgroup analyses were performed on participants who consumed the products for diarrhoea, constipation, Inflammatory Bowel Disease, Irritable Bowel Syndrome, and antibiotic usage. Overall, findings support the potential of probiotics to advance perceived human health and support the daily wellbeing of users. This systematic analysis of user experiences thereby contributes to the external validity of studies evaluating clinical effects of probiotics and increases knowledge on their societal impact.
\end{abstract}

Keywords: health benefits, lactic acid bacteria, quality of life, gastrointestinal health, stool quality

\section{Introduction}

Humans are colonised by trillions of microbes, collectively referred to as the endogenous microbiota. These microorganisms can be found in our oral cavities, skin, urethra, bladder, placenta, lungs and biliary tracts, but are primarily localised in the lower parts of the gastrointestinal tract (GIT) due to the abundance of nutrients in this area (Ley et al., 2006). The GIT microbiota is vital for human health and wellbeing as it helps to produce essential nutrients and protects the host against pathogens (Sánchez et al., 2017), but, when the microbiota is disrupted it becomes a risk factor for disease and frailty (De Vos and De Vos, 2012). Common GIT disorders related to gut microbiota perturbations include irritable bowel syndrome (IBS), inflammatory bowel disease (IBD), diarrhoea, and constipation (De Vos and De Vos, 2012). However, microbiota perturbations may also manifest beyond the GIT, for instance, as mental stress, anxiety, Parkinson's and Alzheimer's disease, psoriasis, obesity, and allergies (Rinninella et al., 2019). Interventions with external microbes, such as many beneficial lactic acid bacteria, 
may prevent or alleviate these conditions by restoring or altering the gut microbiota composition and functionality, inhibiting the growth of pathogens, and supporting immune defence of the host (Hill et al., 2014). These microorganisms are commonly referred to as 'probiotics' and are widely available for consumers and patients in contemporary culture (Markets and Markets, 2018).

Over the past decades, many randomized controlled clinical trials (RCTs) have been performed with a large variety of probiotic species and strains. These studies indicate that probiotics are safe for (oral) human consumption (Van den Nieuwboer and Claassen, 2019; Van den Nieuwboer et al., 2014, 2015a,b), and may improve stool quality, bowel habits and quality of life (QoL), among a wide range of other health benefits (Korterink et al., 2014; Lorenzo-Zúñiga et al., 2014; Venkataraman et al., 2019). Recent meta-analyses support these conclusions and provide an indication of the probiotic effect (Dimidi et al., 2014; Flach et al., 2018). Other studies adopted a qualitative approach by reviewing the perceptions of patients and, similarly, report positive effects on human health after supplementation (Van der Waal et al., 2019). En masse, these studies indicate that probiotics have vast potential to advance human health and support the daily wellbeing of users.

Despite the scientific advances made in recent years on the clinical effects of probiotics, research on their societal impact remains limited. While regulatory agencies, such as the European Food and Safety Authority (EFSA), recommend health claim dossiers to be built on an evidence based RCT approach, such RCTs are not necessarily best suited to assess experiences of users in daily practice and their associated societal impact. Thus, while deemed essential for decisive conclusions on efficacy in pharmaceutical research, innovators in the microbiota field do not always opt to invest in large RCTs (Flach, 2020) but are increasingly exploring alternatives. When taking a broader perspective to societal impact, engagement of end-users is important to discover unmet needs, define relevant health benefits and identify key considerations for successful implementation in daily practice (Van de Burgwal et al., 2018). Systematic analysis of user experiences may hence prove essential to increase the external validity of studies evaluating the clinical effects of probiotics (Schork, 2015), and improve the societal impact of probiotics in general. The present study therefore takes a retrospective approach and uses a database of user experiences to review the effects of four multispecies probiotic formulations and identify approaches forward to conducting such studies in a prospective manner.

\section{Subjects and methods}

\section{Study design}

The purpose of this retrospective study is to evaluate the experiences of probiotics users regarding perceived GIT symptoms, QoL and reported stool consistency. We used a database that contained the feedback of users of four multispecies probiotic formulations obtained between 2015 and 2019.

\section{Database composition}

During the research period, clients of health care professionals (HCP), such as general practitioners (GPs) and dieticians, could opt for a free try-out period with one of four probiotic products in consultation with their treating HCP. The HCP could then apply for the try-out packages on the website of the producer which were sent free of charge to the clients. To provide users with an opportunity to assess the impact of probiotic supplementation on their individual health, a single diary was included in the package as a self-assessment tool to measure subjective experiences prior to-, duringand after use. Probiotic users could choose to return the incorporated questionnaire anonymously to the producer, while providing their consent, so that the company could gain additional insights into the experiences of probiotic users in daily practice, the extent to which the experiences match the scientific evidence used to develop the products, and potentially identify new target groups, indications, and complaints where the products may be effective. No financial compensation was provided for this feedback.

\section{Probiotic products}

The four multispecies probiotic formulations evaluated in this study are produced by Winclove Probiotics (Amsterdam, the Netherlands) and summarized in Table 1. Each (potential) participant received a single try-out package consisting of 14 daily doses, or 7 doses in case of Ecologic ${ }^{\circledR} \mathrm{AAD}$ (refer to Table 1). The intended health indications for which these products have previously been studied is also detailed in Table 1, accompanied by corresponding scientific publications, and include AAD, IBD, constipation and gastrointestinal complaints. Generally, HCPs are informed about probiotics through schooling sessions, scientific literature, information leaflets, colleague experiences or personal contact with producers (Van der Geest et al., 2020). In this study, HCPs were informed about the products by the producer through means of information on the website of the producer, personal visits, conference meetings or telephone inquiries by the HCP. The intervention period was 14 days for all products except for Ecologic AAD, where the intervention period was 7 days. 
Table 1. Multispecies probiotic formulations.

\begin{tabular}{|c|c|c|c|c|}
\hline & $\begin{array}{l}\text { Ecologic AAD } \\
\text { (on the Dutch market as } \\
\text { Winbiotic PRO.AD) }\end{array}$ & $\begin{array}{l}\text { Ecologic } 825 \\
\text { (on the Dutch market as } \\
\text { Winbiotic PRO.IB) }\end{array}$ & $\begin{array}{l}\text { Ecologic Relief } \\
\text { (on the Dutch market as } \\
\text { Winbiotic PRO.CR) }\end{array}$ & $\begin{array}{l}\text { Winclove Adult } \\
\text { (on the Dutch market as } \\
\text { Winbiotic PRO.SC) }\end{array}$ \\
\hline Strains & $\begin{array}{l}\text { Bifidobacterium bifidum W23; } \\
\text { Bifidobacterium lactis W51; } \\
\text { Enterococcus faecium W54; } \\
\text { Lactobacillus acidophilus W37; } \\
\text { L. acidophilus W55; } \\
\text { Lactobacillus paracasei W20; } \\
\text { Lactobacillus plantarum W62; } \\
\text { Lactobacillus rhamnosus W71; } \\
\text { Lactobacillus salivarius W24 }\end{array}$ & $\begin{array}{l}\text { B. bifidum W23; } \\
\text { B. lactis W51; } \\
\text { B. lactis W52; } \\
\text { L. acidophilus W22; } \\
\text { Lactobacillus casei W56; } \\
\text { L. paracasei W20; } \\
\text { L. plantarum W62; } \\
\text { L. salivarius W24; } \\
\text { Lactococcus lactis W19 }\end{array}$ & $\begin{array}{l}\text { B. bifidum W23; } \\
\text { B. lactis W51; } \\
\text { B. lactis W52; } \\
\text { Bifidobacterium longum W108; } \\
\text { L. casei W79; } \\
\text { L. plantarum W62; } \\
\text { L. rhamnosus W71 }\end{array}$ & $\begin{array}{l}\text { B. lactis W51; } \\
\text { B. lactis W52; } \\
\text { E. faecium W54; } \\
\text { L. acidophilus W22; } \\
\text { L. paracasei W20; } \\
\text { L. plantarum W21; } \\
\text { L. salivarius W24; } \\
\text { L. lactis W19 }\end{array}$ \\
\hline cfu per recommended dose & $1 \times 10^{10}$ & $7.5 \times 10^{9}$ & $4 \times 10^{9}$ & $3 \times 10^{9}$ \\
\hline $\begin{array}{l}\text { Intervention period } \\
\text { Studied in }\end{array}$ & $\begin{array}{l}7 \text { days } \\
\text { antibiotic-associated diarrhoea } \\
\text { (Hell et al., 2013; Koning, 2010; } \\
\text { Koning et al., 2008; Lang, 2010; } \\
\text { Van Wietmarschen et al., 2020) }\end{array}$ & $\begin{array}{l}14 \text { days } \\
\text { inflammatory bowel disease } \\
\text { (Hemert et al., 2013; } \\
\text { Lutgendorff, 2009; Mulder, } \\
\text { 2008; Persborn et al., 2013; } \\
\text { Van der Waal et al., 2019) }\end{array}$ & $\begin{array}{l}14 \text { days } \\
\text { Constipation } \\
\text { (Bekkali et al., 2007; } \\
\text { De Milliano et al., 2012) }\end{array}$ & $\begin{array}{l}14 \text { days } \\
\text { gastrointestinal complaints } \\
\text { (Grossenbacher et al., 2016) }\end{array}$ \\
\hline
\end{tabular}

\section{Database population}

There were no restrictions on age or health indication, other than reported on the product's packaging (i.e. not recommended for consumption below the age of 1). Intervention with the products in children under the age of 18 was the responsibility of the parent or legal guardian (who filled out their questionnaire).

\section{Questionnaire design}

The questionnaires were filled out by participants over the course of the 7 or 14-day intervention period. They were developed by the producer based on other QoL and GIT symptom questionnaires and comprised 7 closed questions prior to use; 2 closed questions during use; and 8 closedand 2 open questions on the last day of consumption. It included an assessment on stool consistency with the Bristol Stool Form Scale during use (Amarenco, 2014), an assessment on nine domains of QoL with a 5/10 point rating scale at beginning and end of use, an assessment on the frequency and burden of common GIT symptoms with a $5 / 10$ point rating scale at beginning and end of use (including diarrhoea, constipation, abdominal ache, abdominal cramps, flatulence, bloating, abdominal growl, nausea, and burping), as well as assessments on the likelihood of recommending probiotics, the likelihood of continuing the use of the product, and the perceived effectiveness. A translated overview of the questionnaire is provided in Supplementary Table S2.

Over time, the impact of probiotic supplementation was reviewed twice. First, responses of user experiences were collected using a questionnaire with a scale of 1 till 5 . Afterwards, the collection of user experiences was repeated, this time using a questionnaire with a scale of 1 till 10.

\section{Data and analyses}

In the present study, the outcomes of the scale 5 questionnaire are presented and used for discussion, and the scale 10 questionnaire is used as supplementary material to illustrate consistency of results. The data were summarised in a Microsoft Excel spreadsheet. All analyses were performed on the available data (i.e. all eligible participants who provided completed questionnaires) using the SAS statistical software version 9.4 (Cary, NC, USA). Comparisons were made between baseline and the second week of treatment, or in case of the BSFC the first week of treatment and the second week of treatment. In case of missing data, LOCF technique (Last Observation Carried Forward) was applied. Primary objectives were analysed within each subgroup using paired T-test (for normally distributed data) and Wilcoxon signed-rank test (for nonnormal data). The Shapiro-Wilk test was used for testing the normality of data. A $P$-value of $<0.05$ was considered 
statistically significant. The denominator in all percentage calculations is the number of participants in the relevant treatment group, unless stated otherwise. Open answers were analysed through means of thematic coding. Analyses were performed for five groups; (1) all products combined, (2) Ecologic ${ }^{\circ} \mathrm{AAD}$, (3) Ecologic ${ }^{\circ}$ 825, (4) Ecologic ${ }^{\circ}$ Relief, and (5) Winclove Adult (Table 2). Additional subgroup analyses were performed to identify clinical relevance for users who consumed the products for diarrhoea, constipation, IBS, IBD and antibiotic usage, which were the largest subgroups (excluding general intestinal health and 'others'; Table 2). All tables were stratified by treatment groups. The statistical analysis was performed by an independent contract research organisation.

\section{Excluded questions}

Questions relating to QoL for the scale 10 questionnaire and the QoL parameter 'wellbeing tired' for the scale 5 questionnaire have been excluded from the analysis of this study as their ordering was different from other questions. All questions were phrased horizontally unidirectionally, except for these questions, which were phrased horizontally bidirectionally (i.e. 10 being the best QoL and 10 being the worst QoL respectively), thereby diminishing the internal validity of results on these outcomes (Maeda, 2015).

\section{Compliance}

All data was obtained and processed anonymously without patient identifiable information, and in line with General Data Protection Regulations (GDPR) (EC, 2016).

\section{Limitations}

There was no control group available in the database of this study, and data is therefore analysed in a dependent sample manner. This type of design increases the chance of type I errors and does not allow for statistical interference on confounding variables.

\section{Results}

\section{Survey group characteristics}

In total, 8,220 try-out packages were distributed of which 584 questionnaire responses were included in the database (corresponding with a response rate of 7.1\%). Data cleaning

Table 2. Demographics and indication for use.

\begin{tabular}{|c|c|c|c|c|c|}
\hline & $\begin{array}{l}\text { Combined population } \\
(n=344)\end{array}$ & $\begin{array}{l}\text { Ecologic AAD } \\
(n=112)\end{array}$ & $\begin{array}{l}\text { Ecologic } 825 \\
(n=26)\end{array}$ & $\begin{array}{l}\text { Ecologic Relief } \\
(n=88)\end{array}$ & $\begin{array}{l}\text { Winclove Adult } \\
(n=118)\end{array}$ \\
\hline Mean age in years $(S D)^{a}$ & $55.3(17.9)$ & $56.2(19.9)$ & $51.7(17.4)$ & $52.6(17.6)$ & $57.4(15.9)$ \\
\hline Men $(\%)$ & $76(22.10 \%)$ & $28(25 \%)$ & $6(23.10 \%)$ & $12(13.60 \%)$ & $30(25.40 \%)$ \\
\hline Women (\%) & $268(77.90 \%)$ & $84(75 \%)$ & $20(76.90 \%)$ & $76(86.40 \%)$ & $88(74.60 \%)$ \\
\hline \multicolumn{6}{|l|}{ Health indication for use: } \\
\hline Antibiotics & $42(12.2 \%)$ & $36(32.1 \%)^{b}$ & $1(3.8 \%)$ & $2(2.3 \%)$ & $3(2.5 \%)$ \\
\hline Bloated feeling & $13(3.8 \%)$ & $3(2.7 \%)$ & $0(0 \%)$ & $4(4.5 \%)$ & $6(5.1 \%)$ \\
\hline Chemotherapy & $3(0.9 \%)$ & $2(1.8 \%)$ & $0(0 \%)$ & $0(0 \%)$ & $1(0.8 \%)$ \\
\hline Constipation & $48(14 \%)$ & $5(4.5 \%)$ & $1(3.8 \%)$ & $33(37.5 \%)^{b}$ & $9(7.6 \%)$ \\
\hline Diarrhoea & $37(10.8 \%)$ & $11(9.8 \%)^{b}$ & $2(7.7 \%)$ & $1(1.1 \%)$ & $23(19.5 \%)^{b}$ \\
\hline Eczema/psoriasis & $2(0.6 \%)$ & $1(0.9 \%)$ & $0(0 \%)$ & $1(1.1 \%)$ & $0(0 \%)$ \\
\hline Flatulence & $9(2.6 \%)$ & $0(0 \%)$ & $2(7.7 \%)$ & $1(1.1 \%)$ & $6(5.1 \%)$ \\
\hline Food allergy & $4(1.2 \%)$ & $2(1.8 \%)$ & $1(3.8 \%)$ & $0(0 \%)$ & $1(0.8 \%)$ \\
\hline General intestinal health & $56(16.3 \%)$ & $10(8.9 \%)$ & $4(15.4 \%)$ & $19(21.6 \%)$ & $23(19.5 \%)$ \\
\hline $\mathrm{IBD}^{\mathrm{C}}$ & $12(3.5 \%)$ & $1(0.9 \%)$ & $9(34.6 \%)^{b}$ & $1(1.1 \%)$ & $1(0.8 \%)$ \\
\hline $\mathrm{IBS}^{\mathrm{C}}$ & $41(11.9 \%)$ & $10(8.9 \%)$ & $2(7.7 \%)$ & $11(12.5 \%)^{b}$ & $18(15.3 \%)^{b}$ \\
\hline Other & $65(18.9 \%)$ & $24(21.4 \%)$ & $2(7.7 \%)$ & $15(17 \%)$ & $24(20.3 \%)$ \\
\hline Parasite & $4(1.2 \%)$ & $3(2.7 \%)$ & $0(0 \%)$ & $0(0 \%)$ & $1(0.8 \%)$ \\
\hline Radiotherapy & $1(0.3 \%)$ & $0(0 \%)$ & $1(3.8 \%)$ & $0(0 \%)$ & $0(0 \%)$ \\
\hline Stoma & $4(1.2 \%)$ & $2(1.8 \%)$ & $1(3.8 \%)$ & $0(0 \%)$ & $1(0.8 \%)$ \\
\hline Urinary tract infection & $3(0.9 \%)$ & $2(1.8 \%)$ & $0(0 \%)$ & $0(0 \%)$ & $1(0.8 \%)$ \\
\hline
\end{tabular}


of the scale 5 questionnaire, led to the inclusion of 344 out of the 351 (98\%) available questionnaires in the analysis of this study, with a total of 76 men (22\%) and 268 women (78\%). The mean age in the combined population was 55 years with a standard deviation of 18 years (range 2-92). The primary indications for which probiotic supplementation was used, were general intestinal health (16\%), constipation (14\%) and antibiotic usage (12\%). Other demographics and health indications are summarised in Table 2 . All health indications were patient reported. The subgroups used for additional analyses are also portrayed in Table 2 . For the scale 10 questionnaire, 240 filled-out questionnaires were included in the analysis. Details on the demographics for scale 10 are presented in Supplementary Table S3.

\section{Gastrointestinal symptoms}

\section{Frequency of gastrointestinal symptoms}

After consumption of the probiotic intervention, a statistically significant reduction of $8-18 \%$ on the frequency of all observed GIT symptoms was reported in the combined population, including a reduction in diarrhoea, constipation, abdominal ache, abdominal cramps, flatulence, bloating, abdominal growl, nausea, and burping $(P<0.0005$, Table 3$)$. For Ecologic AAD, Ecologic Relief and Winclove Adult most GIT symptoms showed a similar, statistically significant improvement compared with baseline, as portrayed in Table 3. The effect of Ecologic 825 was statistically significant in two domains (flatulence and abdominal growl; Table 3).

Analysis on the frequency of GIT symptoms for specific product-indication subgroups revealed that a relative improvement from baseline could be observed on most GIT domains for most subgroups, although these were not statistically significant for all domains. The percentage improvement per indication and subdomain are summarised in Supplementary Table S1. For participants consuming Ecologic AAD for antibiotic usage, relative improvements between $0-32 \%$ were reported on the frequency of GIT symptoms, with statistically significant improvements in the nausea, bloating and abdominal growl domains (32\%, $P=0.0005 ; 14 \%, P=0.0178 ; 13 \%, P=0.0493$, respectively). For participants consuming Winclove Adult or Ecologic AAD for diarrhoea, relative improvements between 0-20\% were reported, with statistically significant improvements in the diarrhoea, flatulence, and bloating domains in the Winclove Adult group (15\%, $P=0.0234 ; 15 \%, P=0.0303 ; 14 \%, P=0.0287$, respectively) and no significant findings in the Ecologic AAD group $(n=11)$. For participants consuming Ecologic 825 for IBD, relative improvements between $11-42 \%$ were reported, with statistically significant improvements in the nausea and diarrhoea domains (42\%, $P=0.0133 ; 11 \%$, $P=0.0353$, respectively). For participants consuming Ecologic Relief for constipation, relative improvements between 9-29\% were reported, with statistically significant improvements in the constipation and abdominal ache domains (29\%, $P<0.001 ; 21 \%, P=0.0106$, respectively). For participants consuming Winclove Adult or Ecologic Relief for IBS, relative improvements between 6-45\% were reported, with statistically significant improvements in most domains (Supplementary Table S1).

As shown in Figure 1, all subgroups showed a relative decrease on the combined frequency of GIT symptoms. A statistically significant improvement was reported for participants who consumed Ecologic AAD for antibiotic usage (2.6 vs 2.3, 0.01), Ecologic 825 for IBD (3.2 vs 2.6 $(P<0.01)$, Ecologic Relief for constipation (3.0 vs $2.4, P<0.01)$ and IBS (3.3 vs 2.3, $P<0.001$ ), and Winclove Adult for IBS (3.0 vs $2.7, P<0.001)$.

\section{Burden of gastrointestinal symptoms}

After consumption of the probiotic intervention, a statistically significant reduction of $9-17 \%$ was reported in the combined population on the burden of all GIT symptoms $(P<0.0005$, Table 3$)$. For users of Winclove Adult, Ecologic AAD and Ecologic Relief, a significant improvement was reported compared with baseline on most GIT symptoms, as summarised in Table 3 . The percentage change appeared similar for users of Ecologic 825, but this was not statistically significant $(n=26)$.

Analysis on the burden of GIT symptoms for specific product-indication subgroups revealed that a relative improvement from baseline could be observed on most GIT domains for most subgroups, although these were not statistically significant for all domains. The percentage improvement per indication and subdomain are summarised in Supplementary Table S1. For participants consuming Ecologic AAD for antibiotic usage, relative improvements between $0-26 \%$ were reported on the burden of GIT symptoms, with statistically significant improvements in the diarrhoea, abdominal ache, flatulence, bloating and nausea domains (Supplementary Table S1). For participants consuming Winclove Adult or Ecologic AAD for diarrhoea, relative improvements between 5-39\% were reported, with statistically significant improvements in the bloating domain (27\%, $P=0.0368$; Ecologic AAD) and the flatulence and burping domains $(19 \%, P=0.0117$; $30 \%, P=0.0078$, respectively; Winclove Adult). The burden of diarrhoea was reported to be reduced by 19 and $5 \%$ but this was not statistically significant $(P=0.0781$ and 0.4082, respectively; Supplementary Table S1). For participants consuming Ecologic 825 for IBD, relative improvements between $0-35 \%$ were reported, but these were not statistically significant. For participants consuming Ecologic Relief for constipation, relative improvements between 4-18\% were reported, with a statistically significant improvement in the constipation domain $(18 \%, P<0.005)$. 
Table 3. Probiotics improve gastrointestinal symptoms (frequency and burden). ${ }^{1,2}$

\begin{tabular}{|c|c|c|c|c|c|c|c|c|c|}
\hline & \multicolumn{3}{|c|}{ Combined population $(n=344)$} & \multicolumn{3}{|c|}{ Ecologic AAD ( $n=112)$} & \multicolumn{3}{|c|}{ Ecologic $825(n=26)$} \\
\hline & Baseline & Difference (\%) & $P$-value & Baseline & Difference (\%) & $P$-value & Baseline & Difference (\%) & $P$-value \\
\hline \multicolumn{10}{|c|}{ Frequency GIT symptoms } \\
\hline Diarrhoea & 2.5 & $-0.2(8 \%)$ & 0.0002 & 2.7 & $-0.1(4 \%)$ & 0.2469 & 3 & $-0.2(7 \%)$ & 0.1826 \\
\hline Constipation & 2.3 & $-0.3(13 \%)$ & $<0.0001$ & 2 & $-0.2(10 \%)$ & 0.0702 & 1.8 & $0(0 \%)$ & 0.8867 \\
\hline Abdominal ache & 3 & $-0.3(10 \%)$ & $<0.0001$ & 2.9 & $-0.4(14 \%)$ & 0.0035 & 2.8 & $0(0 \%)$ & 0.8882 \\
\hline Abdominal cramps & 2.9 & $-0.4(14 \%)$ & $<0.0001$ & 2.8 & $-0.4(14 \%)$ & 0.0015 & 3 & $-0.6(20 \%)$ & 0.0571 \\
\hline Flatulence & 3.8 & $-0.5(13 \%)$ & $<0.0001$ & 3.6 & $-0.3(8 \%)$ & 0.0055 & 4 & $-0.7(18 \%)$ & 0.0107 \\
\hline Bloating & 3.4 & $-0.6(18 \%)$ & $<0.0001$ & 3.3 & $-0.7(21 \%)$ & $<0.0001$ & 3.5 & $-0.5(14 \%)$ & 0.0996 \\
\hline Abdominal growl & 3.4 & $-0.5(15 \%)$ & $<0.0001$ & 3.3 & $-0.3(9 \%)$ & 0.0093 & 3.6 & $-0.7(19 \%)$ & 0.0244 \\
\hline Nausea & 2.2 & $-0.4(18 \%)$ & $<0.0001$ & 2 & $-0.4(20 \%)$ & 0.0001 & 2 & $-0.5(25 \%)$ & 0.0887 \\
\hline Burping & 2.5 & $-0.3(12 \%)$ & $<0.0001$ & 2.3 & $-0.3(13 \%)$ & 0.0050 & 2.2 & $-0.3(14 \%)$ & 0.2539 \\
\hline \multicolumn{10}{|l|}{ Burden GIT symptoms } \\
\hline Diarrhoea & 2.6 & $-0.3(12 \%)$ & $<0.0001$ & 2.6 & $-0.3(12 \%)$ & 0.0031 & 2.7 & $-0.1(4 \%)$ & 0.5649 \\
\hline Constipation & 2.2 & $-0.2(9 \%)$ & 0.0029 & 1.9 & $-0.2(11 \%)$ & 0.0567 & 1.8 & $0(0 \%)$ & 1 \\
\hline Abdominal ache & 2.7 & $-0.3(11 \%)$ & $<0.0001$ & 2.5 & $-0.3(12 \%)$ & 0.0062 & 2.7 & $-0.1(4 \%)$ & $0.6336^{*}$ \\
\hline Abdominal cramps & 2.8 & $-0.4(14 \%)$ & $<0.0001$ & 2.6 & $-0.4(15 \%)$ & 0.0032 & 2.6 & $-0.1(4 \%)$ & $0.6325^{\star}$ \\
\hline Flatulence & 3.1 & $-0.4(13 \%)$ & $<0.0001$ & 2.8 & $-0.4(14 \%)$ & 0.0002 & 3.2 & $-0.6(19 \%)$ & 0.0557 \\
\hline Bloating & 2.9 & $-0.5(17 \%)$ & $<0.0001$ & 2.9 & $-0.5(17 \%)$ & $<0.0001$ & 2.8 & $-0.3(11 \%)$ & 0.3918 \\
\hline Abdominal growl & 2.7 & $-0.3(11 \%)$ & $<0.0001$ & 2.5 & $-0.3(12 \%)$ & 0.0182 & 2.9 & $-0.4(14 \%)$ & 0.1543 \\
\hline Nausea & 1.9 & $-0.3(16 \%)$ & $<0.0001$ & 1.9 & $-0.3(16 \%)$ & 0.0006 & 1.9 & $-0.3(16 \%)$ & 0.4727 \\
\hline \multirow[t]{3}{*}{ Burping } & 2 & $-0.3(15 \%)$ & $<0.0001$ & 1.8 & $-0.2(11 \%)$ & 0.0726 & 2 & $0(0 \%)$ & 1 \\
\hline & \multicolumn{3}{|c|}{ Ecologic Relief ( $n=88)$} & \multicolumn{3}{|c|}{ Winclove Adult (n=118) } & & & \\
\hline & Baseline & Difference (\%) & $P$-value & Baseline & Difference (\%) & Wi $P$-value & & & \\
\hline \multicolumn{10}{|c|}{ Frequency GIT symptoms } \\
\hline Diarrhoea & 1.8 & $0(0 \%)$ & 0.6727 & 2.8 & $-0.4(14 \%)$ & $<0.0001$ & & & \\
\hline Constipation & 3.5 & $-1(29 \%)$ & $<0.0001$ & 1.8 & $0(0 \%)$ & 0.8911 & & & \\
\hline Abdominal ache & 3.2 & $-0.5(16 \%)$ & $<0.0001$ & 3.1 & $-0.2(6 \%)$ & 0.0166 & & & \\
\hline Abdominal cramps & 3 & $-0.3(10 \%)$ & 0.0109 & 2.9 & $-0.4(14 \%)$ & 0.0018 & & & \\
\hline Flatulence & 3.8 & $-0.4(11 \%)$ & 0.0011 & 4 & $-0.6(15 \%)$ & $<0.0001$ & & & \\
\hline Bloating & 3.4 & $-0.4(12 \%)$ & 0.0014 & 3.4 & $-0.8(24 \%)$ & $<0.0001$ & & & \\
\hline Abdominal growl & 3.4 & $-0.5(15 \%)$ & 0.0006 & 3.6 & $-0.5(14 \%)$ & $<0.0001$ & & & \\
\hline Nausea & 2.4 & $-0.4(17 \%)$ & 0.0012 & 2.1 & $-0.4(19 \%)$ & $<0.0001$ & & & \\
\hline Burping & 2.7 & $-0.4(15 \%)$ & 0.0008 & 2.6 & $-0.4(15 \%)$ & 0.0003 & & & \\
\hline \multicolumn{10}{|l|}{ Burden GIT symptoms } \\
\hline Diarrhoea & 1.9 & $-0.1(5 \%)$ & 0.3452 & 2.9 & $-0.3(10 \%)$ & 0.0017 & & & \\
\hline Constipation & 3.2 & $-0.7(22 \%)$ & $<0.0001$ & 1.8 & $0.1(-6 \%)$ & 0.3176 & & & \\
\hline Abdominal ache & 2.9 & $-0.4(14 \%)$ & 0.0017 & 2.7 & $-0.3(11 \%)$ & 0.0225 & & & \\
\hline Abdominal cramps & 2.9 & $-0.4(14 \%)$ & 0.0044 & 2.8 & $-0.4(14 \%)$ & 0.0014 & & & \\
\hline Flatulence & 3 & $-0.4(13 \%)$ & 0.0204 & 3.3 & $-0.5(15 \%)$ & $<0.0001$ & & & \\
\hline Bloating & 3.1 & $-0.5(16 \%)$ & 0.0002 & 2.9 & $-0.5(17 \%)$ & $<0.0001$ & & & \\
\hline Abdominal growl & 2.7 & $-0.4(15 \%)$ & 0.0053 & 2.8 & $-0.3(11 \%)$ & 0.0155 & & & \\
\hline Nausea & 2.1 & $-0.3(14 \%)$ & 0.0137 & 1.9 & $-0.3(16 \%)$ & 0.0115 & & & \\
\hline Burping & 2.1 & $-0.2(10 \%)$ & 0.1530 & 2.2 & $-0.5(23 \%)$ & $<0.0001$ & & & \\
\hline
\end{tabular}

\footnotetext{
${ }^{1}$ Measured on a scale of 1-5; with 5 being: (1) the most frequent occurrence of GIT symptoms, and (2) the most severe burden of GIT symptoms. Percentages are the percentage improvement.

2 Paired T-test was used for Gaussian data and Wilcoxon signed-rank test for non-Gaussian data. Paired T-test is indicated with an asterisk (*) if applicable. Significant results are italic. Bold text indicates a deterioration instead of an improvement.
} 
Frequency of GIT symptoms - average scores

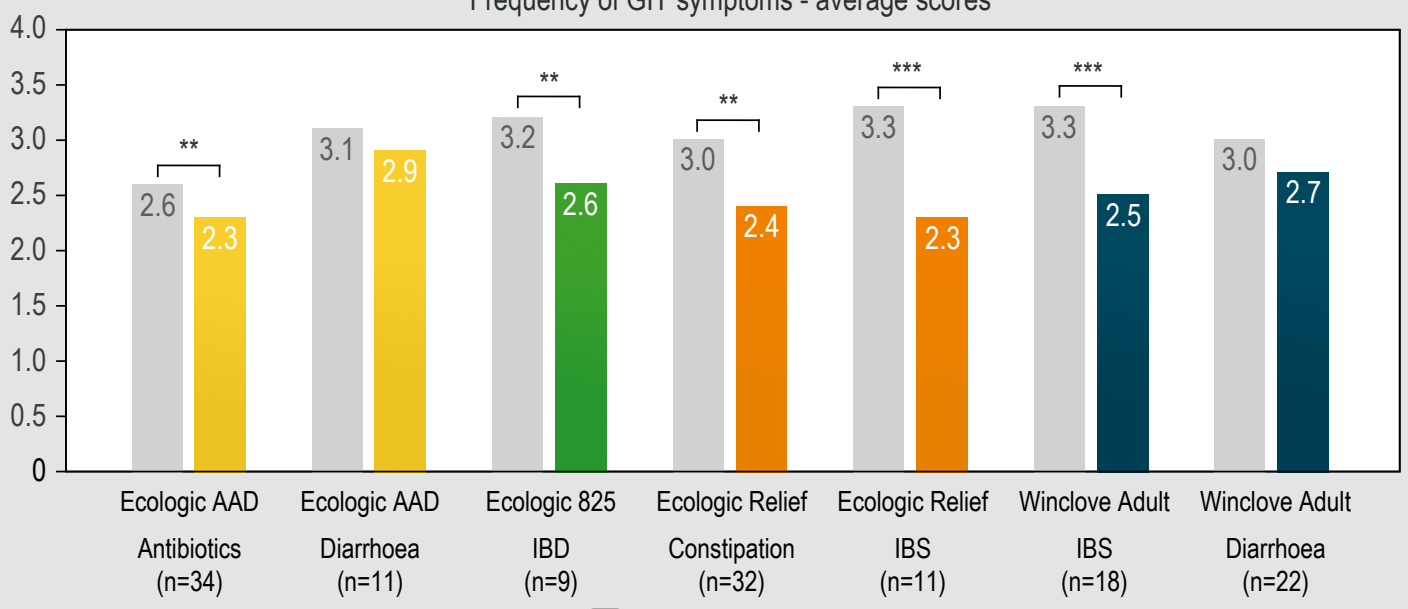

Baseline vs After use

Burden of GIT symptoms - average scores

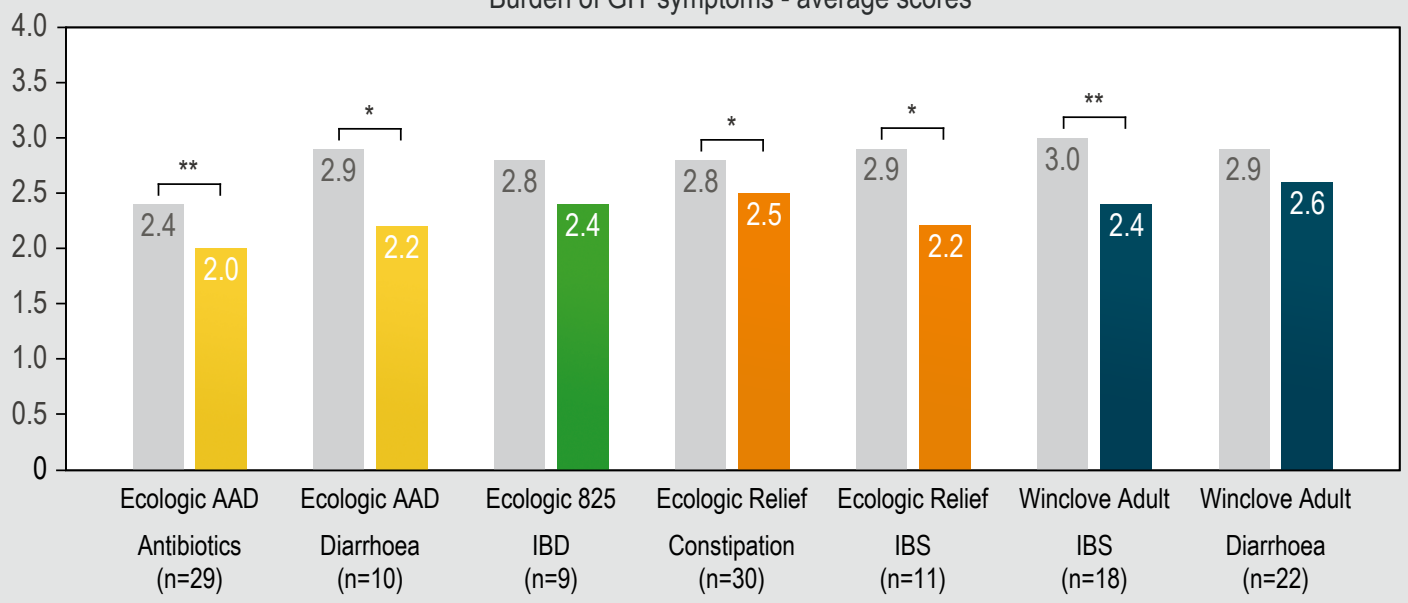

Baseline vs After use

Quality of life - average scores

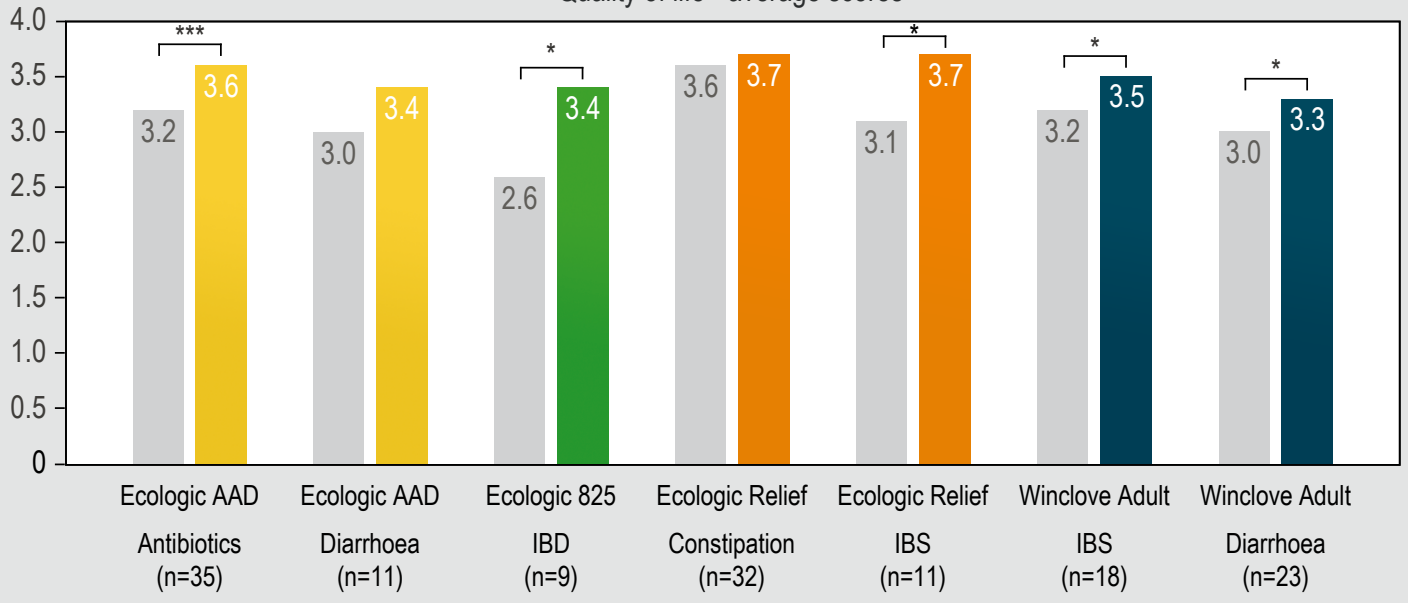

Baseline vs After use

Figure 1. Probiotic effect in subgroups - average scores. This figure portrays the average scores on the frequency and burden of gastrointestinal symptoms and quality of life for the subgroup analysis, as measured on a scale of 1 till 5 . Grey bars represent baseline scores and coloured bars represents post-treatment scores for the different products. A decrease in gastrointestinal symptom scores, and an increase in quality-of-life scores, corresponds with a relative improvement. 
For participants consuming Ecologic Relief or Winclove Adult for IBS, relative improvements between 0-53\% were reported, with statistically significant improvements in the bloating and nausea domains for Ecologic Relief (26\%, $P=0.0418 ; 53 \%, P=0.0313$, respectively) and most domains for Winclove Adult (Supplementary Table S1).

As shown in Figure 1, all subgroups reported a relative decrease on the combined burden of GIT symptoms. A statistically significant improvement was reported for participants who consumed Ecologic AAD for antibiotic usage (2.4 vs 2.0, $P<0.01)$ and diarrhoea ( 2.9 vs $2.2, P<0.05)$, Ecologic Relief for constipation (2.8 vs $2.5, P<0.05)$ and IBS ( 2.9 vs $2.2, P<0.05)$, and Winclove Adult for IBS (3.0 vs $2.4, P<0.01)$.

\section{Comparison with scale 10}

The results on the frequency and burden of GIT symptoms for the scale 10 questionnaire are portrayed in Supplementary Table S4 and S5. Similar results were observed in this questionnaire. However, the Ecologic 825 group reported more statistically significant improvements in the scale 10 questionnaire $(n=67)$ than in the scale 5 questionnaire $(n=26)$ on both the frequency and burden of GIT symptoms (Supplementary Table S4). The users of Ecologic Relief and Winclove Adult, for the indication of IBS, reported fewer statistically significant domains in the scale 10 questionnaire ( $n=6$, for both) compared with the scale 5 questionnaire $(n=11$ and $n=18$, respectively; Supplementary Table S5). Overall, the relative improvements were comparable between questionnaires.

\section{Increase in frequency and burden of gastrointestinal symptoms (adverse effects)}

Increases in GIT symptoms are indicated in bold in Table 3 and Supplementary Table S1. There were no statistically significant increases in the frequency or burden of GIT symptoms following probiotic supplementation.

\section{Quality of life}

After consumption of the probiotic intervention, a statistically significant improvement between 3-19\% was reported in the combined population on all QoL parameters, including an improvement in general health status, social time, social type (of activities), work time, work achievement, work type, energy, sleep, and feelings of happiness $(P<0.005$, Table 4 and Figure 2). For the users of Ecologic AAD, Ecologic Relief and, Winclove Adult most QoL domains showed a significant improvement compared with baseline (Table 4). The relative difference from baseline appeared similar for the Ecologic 825 group, but was only statistically significant for social time, work type, and wellbeing energy (Table 4).

\section{Subgroup analysis - quality of life}

The QoL analysis for specific product-indication subgroups revealed that a relative improvement from baseline could be observed on most QoL domains for most subgroups, although these were not statistically significant for all domains. The largest relative improvement was reported in the wellbeing energy domain (between 6-94\%) and was statistically significant for most subgroups. The percentage improvement per indication and subdomain are summarised in Supplementary Table S1.

As shown in Figure 1, all subgroups reported a relative improvement on the combined QoL scores. A significant improvement was observed for participants who consumed Ecologic AAD for antibiotic use (3.2 vs 3.6, $P<0.001)$, Ecologic 825 for IBD (2.6 vs 3.4, $P<0.05)$, Ecologic Relief for IBS (3.1 vs 3.7, $P<0.05$ ), and Winclove Adult for IBS (3.2 vs $3.5, P<0.01)$ and diarrhoea (3.0 vs $3.3, P<0.05)$.

\section{Decrease in quality of life (adverse effects)}

Decreases in QoL are indicated in bold in Table 3 and Supplementary Table S1. There were no statistically significant decreases in QoL following probiotic supplementation.

\section{Comparison with scale 10}

The results of the scale 10 questionnaire are not reported for this outcome (see Subjects and methods).

\section{Stool consistency and defecation frequency}

Based on defecation frequency and stool consistency (as reported by participants using the BSFC), we made a subdivision of participants with diarrhoea and constipation to determine the relative improvements in these groups. The data presented here are descriptive summaries and have not been evaluated for statistical significance.

\section{Diarrhoea}

To estimate the number of participants with diarrhoea, we used the criterion of the World Health Organization (WHO, 2020), and defined diarrhoea as having 3 or more loose or liquid stools (type 5, 6 or 7 on the BSFC) per day, for at least one day per week.

In the combined population, 78 (27\%) of participants reported to have diarrhoea in week 1 , with a mean number of 3.0 days with diarrhoea. In week 2, 41 (53\%) of these participants reported to no longer have diarrhoea and 13 participants $(17 \%)$ reported fewer days with diarrhoea, whereas 18 (22\%) participants reported the same number of days with diarrhoea and $6(8 \%)$ more days with diarrhoea. In total, the mean reported number of days 
Table 4. Probiotics improve quality of life., ${ }^{1,2}$

\begin{tabular}{|c|c|c|c|c|c|c|c|c|c|}
\hline & \multicolumn{3}{|c|}{ Combined population $(n=344)$} & \multicolumn{3}{|c|}{ Ecologic AAD (n=112) } & \multicolumn{3}{|c|}{ Ecologic $825(n=26)$} \\
\hline & Baseline & Difference (\%) & $P$-value & Baseline & Difference (\%) & $P$-value & Baseline & Difference (\%) & $P$-value \\
\hline Health status & 3.3 & $0.1(3 \%)$ & 0.0008 & 3.3 & $0.1(3 \%)$ & 0.0699 & 3.2 & $0.2(6 \%)$ & 0.1700 \\
\hline Social time & 3.3 & $0.4(12 \%)$ & $<0.0001$ & 3.3 & $0.4(12 \%)$ & $<0.0001$ & 3 & $0.5(17 \%)$ & 0.0287 \\
\hline Social type & 3.2 & $0.4(13 \%)$ & $<0.0001$ & 3.2 & $0.5(16 \%)$ & $<0.0001$ & 3 & $0.4(13 \%)$ & 0.0664 \\
\hline Work time & 3.3 & $0.3(9 \%)$ & $<0.0001$ & 3.2 & $0.3(9 \%)$ & $<0.0001$ & 3.1 & $0.4(13 \%)$ & 0.0938 \\
\hline Work achievement & 3.3 & $0.3(9 \%)$ & $<0.0001$ & 3.3 & $0.3(9 \%)$ & 0.0009 & 3.3 & $0.3(9 \%)$ & 0.2744 \\
\hline Work type & 3.3 & $0.3(9 \%)$ & $<0.0001$ & 3.3 & $0.2(6 \%)$ & 0.0052 & 3 & $0.5(17 \%)$ & 0.0096 \\
\hline Wellbeing energy & 2.7 & $0.5(19 \%)$ & $<0.0001$ & 2.8 & $0.5(18 \%)$ & $<0.0001$ & 2.5 & $0.8(32 \%)$ & 0.0045 \\
\hline Wellbeing sleep & 3.2 & $0.3(9 \%)$ & $<0.0001$ & 3.2 & $0.1(3 \%)$ & 0.1013 & 3 & $0.4(13 \%)$ & 0.0801 \\
\hline \multirow[t]{3}{*}{ Wellbeing happy } & 3.4 & $0.2(6 \%)$ & $<0.0001$ & 3.5 & $0.2(6 \%)$ & 0.0023 & 3.3 & $0.2(6 \%)$ & 0.3633 \\
\hline & \multicolumn{3}{|c|}{ Ecologic Relief ( $n=88)$} & \multicolumn{3}{|c|}{ Winclove Adult ( $n=118$ ) } & & & \\
\hline & Baseline & Difference (\%) & $P$-value & Baseline & Difference (\%) & Wi $P$-value & & & \\
\hline Health status & 3.3 & $0.0(0 \%)$ & 0.4657 & 3.2 & $0.1(3 \%)$ & 0.0172 & & & \\
\hline Social time & 3.5 & $0.3(9 \%)$ & 0.0021 & 3.1 & $0.4(13 \%)$ & $<0.0001$ & & & \\
\hline Social type & 3.4 & $0.3(9 \%)$ & 0.0021 & 3.1 & $0.3(10 \%)$ & $<0.0001$ & & & \\
\hline Work time & 3.5 & $0.1(3 \%)$ & 0.2178 & 3.1 & $0.4(13 \%)$ & $<0.0001$ & & & \\
\hline Work achievement & 3.5 & $0.2(6 \%)$ & 0.156 & 3 & $0.5(17 \%)$ & $<0.0001$ & & & \\
\hline Work type & 3.4 & $0.3(9 \%)$ & 0.0104 & 3.2 & $0.3(9 \%)$ & 0.0002 & & & \\
\hline Wellbeing energy & 2.7 & $0.5(19 \%)$ & $<0.0001$ & 2.7 & $0.5(19 \%)$ & $<0.0001$ & & & \\
\hline Wellbeing sleep & 3.2 & $0.3(9 \%)$ & 0.0049 & 3.2 & $0.3(9 \%)$ & 0.0007 & & & \\
\hline Wellbeing happy & 3.4 & $0.3(9 \%)$ & 0.0021 & 3.3 & $0.1(3 \%)$ & 0.0634 & & & \\
\hline
\end{tabular}

${ }^{1}$ Measured on a scale of 1-5; with 5 being the best Quality of Life. Percentages are the percentage improvement.

2 Wilcoxon signed-rank test was used for non-Gaussian data. Significant results are italic.

with diarrhoea in week 1 was 3.0 days, compared with 1.7 days in week 2 . Results for the other groups are portrayed in Table 5. Alternatively, 210 (73\%) participants did not report to have diarrhoea in week 1 , of which 10 participants (5\%) did report to have developed diarrhoea in week 2 . The mean number of days with diarrhoea was 2.2 days in this group (Table 5).

The reported relative diarrhoea prevalence was highest in the subgroups Ecologic AAD - diarrhoea (4; 67\%), Winclove Adult - diarrhoea (9; 47\%), and Ecologic 825 - IBD (4;56\%). The mean reported number of days with diarrhoea in week 2 decreased in these groups from 4.0 days to 2.0 days, 4.2 days to 3.6 days, and 3.2 days to 2.8 days, respectively (Table 6). In these groups, 2 participants (50\%), 1 participant (11\%), and 3 participants (60\%), no longer reported to have diarrhoea in week 2 , respectively. Additionally, 2 (22\%) participants in the Winclove Adult - diarrhoea group reported fewer days with diarrhoea in week 2. Results for the other subgroups are portrayed in Table 6. There were no participants in the subgroups who did not report to have diarrhoea in week 1 and did report to have developed diarrhoea in week 2 (Table 6).

Results for the scale 10 questionnaire were comparable and are portrayed in Supplementary Tables S6 and S7. The mean reported number of days with diarrhoea were higher, both in week 1 and 2, but effects following probiotic supplementation were similar (3.8 days in week 1, vs 2.65 days in week 2).

\section{Constipation}

To estimate the number of participants with constipation, we initially defined constipation as having fewer than 3 bowel movements per week and having more than $25 \%$ of stools that were hard or lump (type 1 and 2 on the BSFC), based on the Rome-IV criteria (Simren et al., 2017). When using these criteria for constipation, only 1 participant had constipation in week 1 ( $0.35 \%$ of the combined population). This participant consumed Ecologic Relief for the reported indication of constipation (relative constipation prevalence 


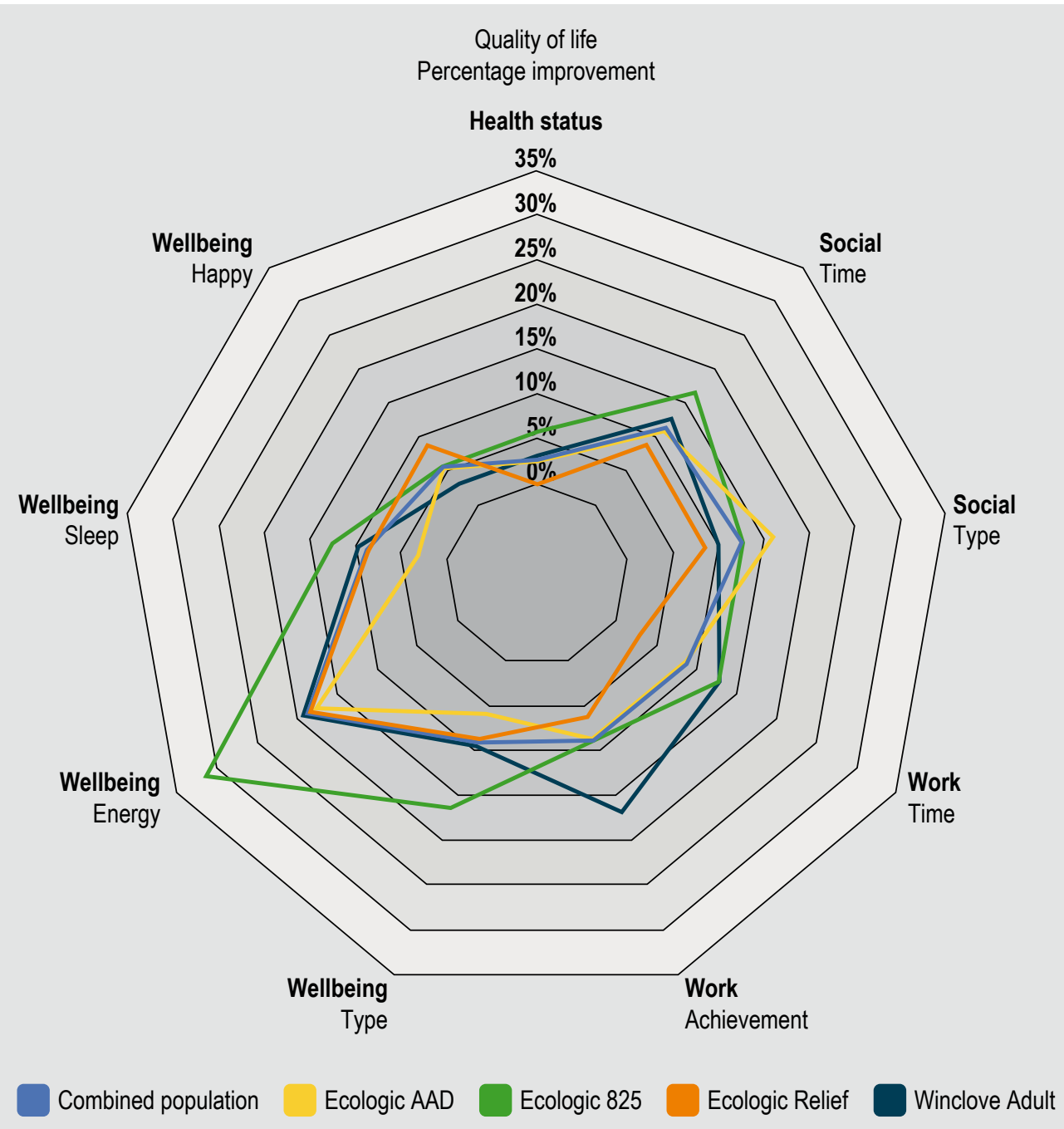

Figure 2. Percentage improvement in quality of life by probiotics. This figure portrays the percentual improvement in quality of life per subdomain compared with baseline for all groups.

in this group was 3\%), and no longer was constipated in week 2 (100\%).

As the initial criteria used for constipation resulted in a low prevalence of constipation (and could be too strict), we re-performed the analysis with the following criteria: having either fewer than 3 bowel movements per week, or having more than $25 \%$ of stools that were hard or lump (type 1 and 2 on the BSFC). Using these alternative criteria, 52 participants $(18 \%)$ of the combined population had constipation in week 1 , of which 19 participants (37\%) no longer were constipated in week 2 . Alternatively, 236 (82\%) of participants did not have constipation in week 1 , of which 35 (15\%) developed constipation in week 2 . The results for other product groups are portrayed in Table 7.

The relative prevalence of constipation was highest in the Ecologic Relief group for the indication of constipation (11; $35 \%)$ and IBS $(4 ; 36 \%)$ in week 1 . Of these participants, 7
(64\%) and 1 (25\%) no longer were constipated in week 2 , respectively (Table 8 ). Results for the other subgroups are portrayed in Table 8.

Results for the scale 10 questionnaire were comparable and are portrayed in Supplementary Tables S8 and S9. In the combined population, 38 participants (18\%) had constipation of which 15 (39\%) no longer were constipated in week 2 .

\section{Perceived effectiveness}

In the combined population, $46 \%$ of participants indicated that they experienced a positive effect of probiotic supplementation that was relevant for the primary health indication for which they used the product (Supplementary Table S10). Alternatively, 26\% of participants indicated that the intervention was not effective enough for their primary health indication, $8 \%$ reported a positive effect on a 
Table 5. Diarrhoea improvement following probiotic supplementation. ${ }^{1}$

\begin{tabular}{|c|c|c|c|c|}
\hline \multirow{3}{*}{$\begin{array}{l}\text { Combined } \\
\text { population } \\
(\mathrm{n}=288)\end{array}$} & \multicolumn{2}{|c|}{ Week 1, n (\%) } & \multicolumn{2}{|l|}{ Week 2, n (\%) } \\
\hline & \multirow[t]{4}{*}{ diarrhoea } & \multirow[t]{4}{*}{$78(27 \%)$} & $\begin{array}{l}\text { no diarrhoea } \\
\text { diarrhoea }\end{array}$ & 41 (53\%) \\
\hline & & & fewer days & $13(17 \%)$ \\
\hline & & & equal days & $18(22 \%)$ \\
\hline & & & more days & $6(8 \%)$ \\
\hline & mean days & 2.99 & mean days ${ }^{2}$ & 1.71 \\
\hline & no diarrhoea & $210(73 \%)$ & no diarrhoea & $200(95 \%)$ \\
\hline & & & diarrhoea & $10(5 \%)$ \\
\hline & & & mean days & 2.22 \\
\hline \multirow{9}{*}{$\begin{array}{l}\text { Ecologic } \\
\text { AAD }(n=70)\end{array}$} & \multirow[t]{5}{*}{ diarrhoea } & \multirow[t]{5}{*}{$22(31 \%)$} & no diarrhoea & $13(59 \%)$ \\
\hline & & & diarrhoea & \\
\hline & & & fewer days & $4(18 \%)$ \\
\hline & & & equal days & $5(23 \%)$ \\
\hline & & & more days & $0(0 \%)$ \\
\hline & mean days & 3.77 & mean days & 1.73 \\
\hline & \multirow[t]{3}{*}{ no diarrhoea } & \multirow[t]{3}{*}{$48(69 \%)$} & no diarrhoea & 47 (98\%) \\
\hline & & & diarrhoea & $1(2 \%)$ \\
\hline & & & mean days & 6.00 \\
\hline \multirow{9}{*}{$\begin{array}{l}\text { Ecologic } \\
825(n=25)\end{array}$} & \multirow[t]{5}{*}{ diarrhoea } & \multirow[t]{5}{*}{$10(40 \%)$} & no diarrhoea & $5(50 \%)$ \\
\hline & & & diarrhoea & \\
\hline & & & fewer days & $0(0 \%)$ \\
\hline & & & equal days & $4(40 \%)$ \\
\hline & & & more days & $1(10 \%)$ \\
\hline & mean days & 3.70 & mean days & 3.00 \\
\hline & \multirow[t]{3}{*}{ no diarrhoea } & \multirow[t]{3}{*}{$15(60 \%)$} & no diarrhoea & $15(100 \%)$ \\
\hline & & & diarrhoea & $0(0 \%)$ \\
\hline & & & mean days & N.A. \\
\hline \multirow{9}{*}{$\begin{array}{l}\text { Ecologic } \\
\text { Relief } \\
(n=84)\end{array}$} & \multirow[t]{5}{*}{ diarrhoea } & \multirow[t]{5}{*}{$13(15 \%)$} & no diarrhoea & $7(54 \%)$ \\
\hline & & & diarrhoea & \\
\hline & & & fewer days & $4(31 \%)$ \\
\hline & & & equal days & $2(15 \%)$ \\
\hline & & & more days & $0(0 \%)$ \\
\hline & mean days & 2.15 & mean days & 1.00 \\
\hline & \multirow[t]{3}{*}{ no diarrhoea } & \multirow[t]{3}{*}{$71(85 \%)$} & no diarrhoea & $68(96 \%)$ \\
\hline & & & diarrhoea & $3(4 \%)$ \\
\hline & & & mean days & 2.33 \\
\hline \multirow{9}{*}{$\begin{array}{l}\text { Winclove } \\
\text { Adult } \\
(n=109)\end{array}$} & \multirow[t]{5}{*}{ diarrhoea } & \multirow[t]{5}{*}{$33(30 \%)$} & no diarrhoea & $16(48 \%)$ \\
\hline & & & diarrhoea & \\
\hline & & & fewer days & $5(15 \%)$ \\
\hline & & & equal days & $7(22 \%)$ \\
\hline & & & more days & $5(15 \%)$ \\
\hline & mean days & 2.58 & mean days & 1.58 \\
\hline & \multirow[t]{3}{*}{ no diarrhoea } & $76(70 \%)$ & no diarrhoea & 70 (92\%) \\
\hline & & & diarrhoea & $6(8 \%)$ \\
\hline & & & mean days & 1.50 \\
\hline
\end{tabular}

\footnotetext{
${ }^{1}$ Diarrhoea is defined as 3 or more loose or liquid stools (type 5,6 or 7 BSFC) per day, at least 1 day per week.

${ }^{2}$ Mean number of days with diarrhoea (defined as above) in week 2 , in participants with diarrhoea in week 1.
}

different health indication and 5\% reported adverse effects (which were primary related to minor GIT complaints such as abdominal growls, cramps, and flatulence). In addition, $13 \%$ of participants indicated to be uncertain about the perceived effectiveness and $2 \%$ of participants provided other comments (which were not directly related to perceived effectiveness). Similar results were observed for the perceived effectiveness in the scale 10 questionnaire, as summarised in Supplementary Table S12 and Figure S1.

\section{Continued use and likelihood of recommendation}

In total, $64 \%$ of participants indicated that they would continue using the product, with the highest percentage of users indicating continued use in the Ecologic 825 group (74\%) (Supplementary Table S13). For all groups, the average likelihood of recommending the product to others was 6 out of 10 (standard deviation 2.9), and 62\% of users reported a 6 or higher (10 being the most likely to recommend). Here, the highest score was also observed among the Ecologic 825 users (6.5, standard deviation 2.7) (Supplementary Table S11). The primary reason for wanting to continue using the products was a perceived positive effect (80\%). Other reasons included curiosity towards long(er) term effects (46\%), curiosity towards continued positive effects $(17 \%)$ or recommendation by treating physician (6\%) [multiple answers possible]. The primary reason for not wanting to continue using the product $(80 \%$ of users not wanting to continue) was that the product was not deemed effective (enough). Other reasons included a disliked taste (9\%), negative effects (9\%), too expensive (9\%), an inactive disease (4\%), or deemed not more effective than other medications (4\%) [multiple answers possible]. For the scale 10 questionnaire, the likelihood of recommendation was comparable but measured in a smaller sample (6.6; $\mathrm{n}=9$; Supplementary Table S13)

\section{Discussion and conclusions}

The present study set out to assess the impact of probiotic supplementation on perceived human health and wellbeing based on the feedback of probiotic users. The core findings of this study elucidate a statistically significant overall improvement on the perceived frequency and burden of common gastrointestinal symptoms, as well as a statistically significant increase in perceived quality of life among users. Descriptive summaries also indicate that diarrhoea-and constipation-like stool patterns are reduced following supplementation. These findings reinforce the idea that probiotics have significant potential to advance perceived human health and support the daily wellbeing of users.

The products used in this study were initially developed for specific indications and have previously been evaluated in an indication-specific manner (Table 1). In line with 
Table 6. Subgroup analysis: diarrhoea improvement following probiotic supplementation. ${ }^{1,2}$

\begin{tabular}{|c|c|c|c|c|}
\hline \multirow{5}{*}{$\begin{array}{l}\text { Ecologic } \\
A A D(n=22), \\
\text { antibiotic } \\
\text { usage }\end{array}$} & \multicolumn{2}{|c|}{ Week 1, n (\%) } & \multicolumn{2}{|l|}{ Week 2, n (\%) } \\
\hline & \multirow[t]{5}{*}{ diarrhoea } & \multirow[t]{5}{*}{$4(18 \%)$} & no diarrhoea & $2(50 \%)$ \\
\hline & & & diarrhoea & \\
\hline & & & fewer days & $0(0 \%)$ \\
\hline & & & equal days & $2(50 \%)$ \\
\hline & & & more days & $0(0 \%)$ \\
\hline & mean days & 4.75 & mean days ${ }^{3}$ & 3.50 \\
\hline & no diarrhoea & $18(82 \%)$ & no diarrhoea & $18(100 \%)$ \\
\hline & & & diarrhoea & $0(0 \%)$ \\
\hline & & & mean days & n.a. \\
\hline \multirow{9}{*}{$\begin{array}{l}\text { Ecologic } \\
A A D(n=6) \\
\text { diarrhoea }\end{array}$} & \multirow[t]{5}{*}{ diarrhoea } & \multirow[t]{5}{*}{$4(67 \%)$} & no diarrhoea & $2(50 \%)$ \\
\hline & & & diarrhoea & \\
\hline & & & fewer days & $0(0 \%)$ \\
\hline & & & equal days & $2(50 \%)$ \\
\hline & & & more days & $0(0 \%)$ \\
\hline & mean days & 4.00 & mean days & 2.00 \\
\hline & \multirow[t]{3}{*}{ no diarrhoea } & \multirow[t]{3}{*}{$2(33 \%)$} & no diarrhoea & $2(100 \%)$ \\
\hline & & & diarrhoea & $0(0 \%)$ \\
\hline & & & mean days & n.a. \\
\hline \multirow{9}{*}{$\begin{array}{l}\text { Ecologic } 825 \\
(n=9), I B D\end{array}$} & \multirow{5}{*}{ diarrhoea } & \multirow[t]{5}{*}{$5(56 \%)$} & no diarrhoea & $3(60 \%)$ \\
\hline & & & diarrhoea & \\
\hline & & & fewer days & $0(0 \%)$ \\
\hline & & & equal days & $1(20 \%)$ \\
\hline & & & more days & $1(20 \%)$ \\
\hline & mean days & 3.20 & mean days & 2.80 \\
\hline & \multirow[t]{3}{*}{ no diarrhoea } & \multirow[t]{3}{*}{$4(44 \%)$} & no diarrhoea & $4(100 \%)$ \\
\hline & & & diarrhoea & $0(0 \%)$ \\
\hline & & & mean days & n.a. \\
\hline \multirow{9}{*}{$\begin{array}{l}\text { Ecologic } \\
\text { Relief ( } n=31) \text {, } \\
\text { constipation }\end{array}$} & \multirow[t]{5}{*}{ diarrhoea } & \multirow[t]{5}{*}{$8(26 \%)$} & no diarrhoea & $6(75 \%)$ \\
\hline & & & diarrhoea & \\
\hline & & & fewer days & $1(13 \%)$ \\
\hline & & & equal days & $1(13 \%)$ \\
\hline & & & more days & $0(0 \%)$ \\
\hline & mean days & 1.88 & mean days & 0.5 \\
\hline & \multirow[t]{3}{*}{ no diarrhoea } & \multirow[t]{3}{*}{$23(74 \%)$} & no diarrhoea & $23(100 \%)$ \\
\hline & & & diarrhoea & $0(0 \%)$ \\
\hline & & & mean days & n.a. \\
\hline \multirow{9}{*}{$\begin{array}{l}\text { Ecologic } \\
\text { Relief }(n=11) \text {, } \\
\text { IBS }\end{array}$} & \multirow[t]{5}{*}{ diarrhoea } & \multirow[t]{5}{*}{$0(0 \%)$} & no diarrhoea & n.a. \\
\hline & & & diarrhoea & \\
\hline & & & fewer days & n.a. \\
\hline & & & equal days & n.a. \\
\hline & & & more days & n.a. \\
\hline & mean days & N.A. & mean days & n.a. \\
\hline & \multirow[t]{3}{*}{ no diarrhoea } & $11(100 \%)$ & no diarrhoea & $11(100 \%)$ \\
\hline & & & diarrhoea & $0(0 \%)$ \\
\hline & & & mean days & n.a. \\
\hline
\end{tabular}

Table 6. Continued. ${ }^{1,2}$

\begin{tabular}{|c|c|c|c|c|}
\hline \multirow{4}{*}{$\begin{array}{l}\text { Winclove } \\
\text { Adult ( } n=18) \text {, } \\
\text { IBS }\end{array}$} & \multicolumn{2}{|c|}{ Week 1, n (\%) } & \multicolumn{2}{|c|}{ Week 2, n (\%) } \\
\hline & \multirow[t]{5}{*}{ diarrhoea } & \multirow[t]{5}{*}{$7(39 \%)$} & no diarrhoea & $3(42 \%)$ \\
\hline & & & diarrhoea & \\
\hline & & & fewer days & $2(29 \%)$ \\
\hline & & & equal days & $2(29 \%)$ \\
\hline & & & more days & $0(0 \%)$ \\
\hline & mean days & 2.71 & mean days & 1.14 \\
\hline & \multirow[t]{3}{*}{ no diarrhoea } & \multirow[t]{3}{*}{$11(61 \%)$} & no diarrhoea & $11(100 \%)$ \\
\hline & & & diarrhoea & $0(0 \%)$ \\
\hline & & & mean days & n.a. \\
\hline \multirow{9}{*}{$\begin{array}{l}\text { Winclove } \\
\text { Adult ( } n=19) \text {, } \\
\text { diarrhoea }\end{array}$} & \multirow[t]{5}{*}{ diarrhoea } & \multirow[t]{5}{*}{$9(47 \%)$} & no diarrhoea & $1(11 \%)$ \\
\hline & & & diarrhoea & \\
\hline & & & fewer days & $2(22 \%)$ \\
\hline & & & equal days & $4(44 \%)$ \\
\hline & & & more days & $2(22 \%)$ \\
\hline & mean days & 4.22 & mean days & 3.56 \\
\hline & \multirow[t]{3}{*}{ no diarrhoea } & \multirow[t]{3}{*}{$10(53 \%)$} & no diarrhoea & $10(100 \%)$ \\
\hline & & & diarrhoea & $0(0 \%)$ \\
\hline & & & mean days & n.a. \\
\hline
\end{tabular}

${ }^{1}$ Diarrhoea is defined as 3 or more loose or liquid stools (type 5,6 or 7 BSFC) per day, at least 1 day per week.

${ }^{2}$ IBS = irritable bowel syndrome; IBD = inflammatory bowel disease; n.a. = not applicable.

${ }^{3}$ Mean number of days with diarrhoea (defined as above) in week 2, in participants with diarrhoea in week 1.

these studies, our results showed indication-specific health benefits. For instance, constipated probiotic users experienced a significant reduction in the frequency and burden of perceived constipation complaints, and constipation-like stool patterns appear to be lowered following supplementation (although descriptive summaries of the latter warrant statistical conformation) in line with Bekkali et al. (2007) and De Milliano et al. (2012). However, it becomes clear that in practice, these probiotics were used for a wide variety of (other) indications (Table 2). Our results show that potentially, positive effects can be achieved on other components of perceived human health, which have not been previously evaluated for these products. For example, the results of the overall population showed a general improvement in perceived GIT complaints and QoL, with a strong improvement in energy reported among probiotic users across health indications. Therefore, the results of this study help to support the scientific rationale for the development of indication-specific probiotic formulations but may also provide insight into more general health effects of supplementation. This being said, placebocontrolled confirmation research is warranted to exclude potential confounding variables in this regard. The potential 
Table 7. Constipation improvement following probiotic supplementation. ${ }^{1}$

\begin{tabular}{|c|c|c|c|c|}
\hline \multirow{4}{*}{$\begin{array}{l}\text { Combined } \\
\text { population } \\
(n=288)\end{array}$} & \multicolumn{2}{|l|}{ Week 1, n (\%) } & \multicolumn{2}{|l|}{ Week 2, n (\%) } \\
\hline & constipation & $52(18 \%)$ & $\begin{array}{l}\text { no constipation } \\
\text { constipation }\end{array}$ & $\begin{array}{l}19(37 \%) \\
33(63 \%)\end{array}$ \\
\hline & \multirow[t]{2}{*}{ no constipation } & \multirow[t]{2}{*}{$236(82 \%)$} & no constipation & $201(85 \%)$ \\
\hline & & & constipation & $35(15 \%)$ \\
\hline \multirow{4}{*}{$\begin{array}{l}\text { Ecologic AAD } \\
(n=70)\end{array}$} & \multirow{2}{*}{ constipation } & \multirow[t]{2}{*}{$8(11 \%)$} & no constipation & $3(38 \%)$ \\
\hline & & & constipation & $5(62 \%)$ \\
\hline & \multirow[t]{2}{*}{ no constipation } & \multirow[t]{2}{*}{$62(89 \%)$} & no constipation & $52(84 \%)$ \\
\hline & & & constipation & $10(16 \%)$ \\
\hline \multirow{4}{*}{$\begin{array}{l}\text { Ecologic } 825 \\
(n=25)\end{array}$} & \multirow[t]{2}{*}{ constipation } & \multirow[t]{2}{*}{$4(16 \%)$} & no constipation & $0(0 \%)$ \\
\hline & & & constipation & $4(100 \%)$ \\
\hline & \multirow[t]{2}{*}{ no constipation } & \multirow[t]{2}{*}{$21(84 \%)$} & no constipation & $19(90 \%)$ \\
\hline & & & constipation & $2(10 \%)$ \\
\hline \multirow{4}{*}{$\begin{array}{l}\text { Ecologic } \\
\text { Relief } \\
(n=84)\end{array}$} & \multirow[t]{2}{*}{ constipation } & \multirow[t]{2}{*}{$26(31 \%)$} & no constipation & $10(38 \%)$ \\
\hline & & & constipation & $16(62 \%)$ \\
\hline & \multirow[t]{2}{*}{ no constipation } & \multirow[t]{2}{*}{$58(69 \%)$} & no constipation & $50(86 \%)$ \\
\hline & & & constipation & $8(14 \%)$ \\
\hline \multirow{4}{*}{$\begin{array}{l}\text { Winclove } \\
\text { Adult } \\
(n=109)\end{array}$} & \multirow[t]{2}{*}{ constipation } & \multirow[t]{2}{*}{$14(13 \%)$} & no constipation & $6(43 \%)$ \\
\hline & & & constipation & $8(57 \%)$ \\
\hline & \multirow[t]{2}{*}{ no constipation } & \multirow[t]{2}{*}{95 (87\%) } & no constipation & $80(84 \%)$ \\
\hline & & & constipation & $15(16 \%)$ \\
\hline
\end{tabular}

${ }^{1}$ Constipation is defined as having either fewer than 3 bowel movements per week, or more than $25 \%$ of stools that are hard or lumpy (type 1 or 2 BSFC).

of probiotics to induce both general and specific health effects, as reported by Hill and colleagues (2014), might explain the wide variety of indications for which probiotics are used and why users and healthcare professionals are experiencing difficulties with choosing the right product for the right indication (Flach et al., 2017; Sanders et al., 2011; Van den Nieuwboer et al., 2016; Van der Geest et al., 2020). Additionally, restrictions on marketing health claims in absence of EFSA approval, make it challenging to communicate the intended health indications from producer to consumer. In combination with limited availability of guidelines for HCPs, practitioners may find it challenging to choose the optimal product (with the most suitable strains) for the primary indication to treat, thereby underutilizing the probiotic health potential. In this regard, the present study provides valuable insights into the direction and magnitude of probiotic effects and might support the formation of guidelines for users and healthcare professionals to choose the most effective probiotic product, thereby fostering implementation in daily practice and the societal impact of probiotic supplementation.

This study had a relatively large sample size which resulted in sufficient power to evaluate the relative outcomes in
Table 8. Subgroup analysis: constipation improvement following probiotic supplementation. ${ }^{1,2}$

\begin{tabular}{|c|c|c|c|c|}
\hline \multirow{5}{*}{$\begin{array}{l}\text { Ecologic } \\
A A D(n=22), \\
\text { antibiotic } \\
\text { usage }\end{array}$} & \multicolumn{2}{|l|}{ Week 1, n (\%) } & \multicolumn{2}{|l|}{ Week 2, n (\%) } \\
\hline & \multirow[t]{2}{*}{ constipation } & \multirow[t]{2}{*}{$1(5 \%)$} & no constipation & $1(100 \%)$ \\
\hline & & & constipation & $0(0 \%)$ \\
\hline & \multirow[t]{2}{*}{ no constipation } & \multirow[t]{2}{*}{$21(95 \%)$} & no constipation & $16(76 \%)$ \\
\hline & & & constipation & $5(24 \%)$ \\
\hline \multirow{4}{*}{$\begin{array}{l}\text { Ecologic } \\
\operatorname{AAD}(n=6) \\
\text { diarrhoea }\end{array}$} & \multirow[t]{2}{*}{ constipation } & \multirow[t]{2}{*}{$0(0 \%)$} & no constipation & n.a. \\
\hline & & & & n.a. \\
\hline & \multirow[t]{2}{*}{ no constipation } & \multirow[t]{2}{*}{$6(100 \%)$} & no constipation & $5(83 \%)$ \\
\hline & & & & \\
\hline \multirow{4}{*}{$\begin{array}{l}\text { Ecologic } \\
825(n=9) \\
\text { IBD }\end{array}$} & \multirow[t]{2}{*}{ constipation } & \multirow[t]{2}{*}{$0(0 \%)$} & no constipation & n.a. \\
\hline & & & constipation & n.a. \\
\hline & \multirow[t]{2}{*}{ no constipation } & \multirow[t]{2}{*}{$9(100 \%)$} & no constipation & $8(89 \%)$ \\
\hline & & & & \\
\hline \multirow{4}{*}{$\begin{array}{l}\text { Ecologic } \\
\text { Relief } \\
(n=31) \\
\text { constipation }\end{array}$} & \multirow[t]{2}{*}{ constipation } & \multirow[t]{2}{*}{$11(35 \%)$} & no constipation & $7(64 \%)$ \\
\hline & & & constipation & $4(36 \%)$ \\
\hline & \multirow[t]{2}{*}{ no constipation } & \multirow[t]{2}{*}{$20(65 \%)$} & no constipation & $17(85 \%)$ \\
\hline & & & & \\
\hline Ecologic & \multirow[t]{2}{*}{ constipation } & \multirow[t]{2}{*}{$4(36 \%)$} & no constipation & $1(25 \%)$ \\
\hline Relief & & & constipation & $3(75 \%)$ \\
\hline$(n=11)$, & \multirow[t]{2}{*}{ no constipation } & \multirow[t]{2}{*}{$7(64 \%)$} & no constipation & $6(86 \%)$ \\
\hline IBS & & & constipation & $1(14 \%)$ \\
\hline Winclove & \multirow[t]{2}{*}{ constipation } & \multirow[t]{2}{*}{$1(6 \%)$} & no constipation & $0(0 \%)$ \\
\hline Adult & & & constipation & $1(100 \%)$ \\
\hline & \multirow[t]{2}{*}{ no constipation } & \multirow[t]{2}{*}{$17(94 \%)$} & no constipation & $14(82 \%)$ \\
\hline IBS & & & constipation & $3(18 \%)$ \\
\hline Winclove & \multirow[t]{2}{*}{ constipation } & \multirow[t]{2}{*}{$2(11 \%)$} & no constipation & $1(50 \%)$ \\
\hline Adult & & & constipation & $1(50 \%)$ \\
\hline & no constipation & $17(89 \%)$ & no constipation & $16(94 \%)$ \\
\hline diarrhoea & & & constipation & $1(6 \%)$ \\
\hline
\end{tabular}

${ }^{1}$ Constipation is defined as having either fewer than 3 bowel movements per week, or more than $25 \%$ of stools that are hard or lumpy (type 1 or 2 BSFC).

${ }^{2}$ IBS = irritable bowel syndrome; IBD = inflammatory bowel disease; n.a. $=$ not applicable.

the combined population. Nonetheless, within certain subgroups the sample size was considered too small to capture all effects from a statistical perspective. For instance, the Ecologic 825 group had a relatively small number of participants $(n=26)$ and relatively few statistically significant differences were observed on the reported frequency and burden of GIT symptoms (in the scale 5 questionnaire). When we consider the relative improvement for this group, however, it becomes clear that the reported effects were comparable to other probiotic groups and the scale 10 questionnaire (which were statistically significant). To put the relative change into perspective, we evaluated the number of participants that would have been needed to reach statistical significance 
in a post hoc sample size calculation. To this end, we used the frequency of bloating as an example, as the relative change was the same (14\%) in both the scale 5 and scale 10 questionnaire for the Ecologic 825 group. It appears that at least 52 participants are required to have $80 \%$ chance of detecting, statistically significant at the 0.05 level, an improvement of $14 \%$ compared with baseline. In line with this sample size calculation, the 26 participants in the scale 5 questionnaire were not enough to observe a statistically significant difference, whereas the scale 10 questionnaire with 67 participants did show a statistically significant difference for the same relative improvement. For this reason, all indication-specific subgroups warrant similar consideration regarding statistical significance, as they generally showed substantial relative improvements but had a relatively small sample size ( $\mathrm{n}$ between 9 and 36 ), and thus require further investigation in a larger population.

In this study, we estimated the number of participants with constipation or diarrhoea based on adaptations of WHO and Rome-IV criteria. For instance, diarrhoea is defined by the WHO as 'the passage of 3 or more loose or liquid stools per day, or more frequently than is normal for the individual' (WHO, 2020). In this study, we used 3 or more reported loose or liquid stools per day as criterion for having diarrhoea. Descriptive summaries then indicate that probiotic consumption may clear - or reduce the number of days with diarrhoea (but this warrants further confirmation as statistical tests for significance were not applied), both in users who reported using the products for diarrhoea and constipation (the latter likely being attributed to the presence of overflow diarrhoea as part of the constipation complaints; Rangan, 2019). However, participants may have experienced more loose or liquid stools than is normal for them in week 1 (but below the cut-off point of $>3$ stools), which according to the WHO definition would also indicate diarrhoea. As this retrospective study did not evaluate 'normal' individual stool frequency and consistency, our findings may underestimate the prevalence of diarrhoea. Similarly, Rome-IV defines constipation as having at least 2 of the following symptoms: (1) straining in more than $25 \%$ of defecations, (2) lumpy or hard stools in more than $25 \%$ of defecations, (3) sensation of incomplete evacuation in more than $25 \%$ of defecations, (4) sensation of anorectal obstruction in more than $25 \%$ of defecations, (5) manual manoeuvres to facilitate more than $25 \%$ of defecations, and (6) fewer than 3 spontaneous bowel movements per week. In this study, we were only able to evaluate 2 of these criteria, and therefore used both defecation frequency and stool consistency as a measure to indicate constipation. The prevalence of constipation may hence be underestimated, as is supported by the low constipation rate $(<1 \%)$. To this end, we adjusted the criterion for constipation in a sensitivity analysis to having either lumpy or hard stools in more than $25 \%$ of defecations, or having fewer than 3 spontaneous bowel movements per week, where the assumption is that any of the other criteria for constipation as reported by Rome-IV are also met. According to this criterion, only $18 \%$ of users in the combined population (who reported using the product for constipation) had constipation. En masse, $55 \%$ of users did not have diarrhoea- or constipation-like stool patterns in this study (according to the definitions we used), suggestive of a more normal stool pattern, yet still experienced unresolved complaints for which they consumed probiotics. Our results therefore reinforce the idea that objective measures such as the BSFC or certain clinical diagnoses are not necessarily aligned with patient experiences (Chumpitazi et al., 2016), thereby further underlining the importance of conducting studies that evaluate user experiences in a subjective manner.

Although no formal safety assessments have been performed in this study, the adverse effects reported by probiotic users indicate that oral consumption of the products was safe. Most users reported no adverse effects, whereas minor GIT complaints were reported by $5 \%$ of users. Commonly reported complaints included increases in gas and bloating, which is consistent with previous studies and therefore expected (Van den Nieuwboer et al., 2019). Additionally, we show that a proportion of users who used the products for constipation had an increase in reported diarrhoea complaints, whereas some users who consumed the products for diarrhoea had in increase in reported constipation complaints. Both increases were, however, statistically insignificant. These effects were evident from the GIT symptom assessment but also demonstrated in the stool consistency and defecation frequency evaluations. For instance, $5 \%$ of the combined population indicated to have developed diarrhoea following supplementation, and $15 \%$ to have developed constipation. Typically, these adverse effects abate after a few weeks of continued use and fluctuation between different stool types are expected in the first weeks of probiotic consumption (Kligler and Cohrssen, 2008).

The gut microbiota composition is affected by aging and associated changes in lifestyle, medication use, dietary habits, and exercise frequency (Odamaki et al., 2016; Rinninella et al., 2019; Yatsunenko et al., 2012). In this regard, the gut microbiota composition of children, adults, and elderly (as a group) may be different from one another, in addition to the between-person variation. Therefore, the effects of probiotic supplementation on outcomes such as QoL, GIT symptoms and bowel habits may be different among age groups. As most of the participants in the present study were adults (95\% confidence interval: 53.3-57.3 years of age), the results and conclusion primarily relate to this age group, and thus warrant further evaluation among different age groups in follow-up studies. 
Lastly, the effects for users in the Ecologic AAD group for the indication of antibiotic usage were difficult to determine. The rationale to take probiotics during antibiotic use is to prevent Antibiotic Associated Diarrhoea (AAD) (Agamennone et al., 2018). Hence, this product may have been used to prevent AAD rather than to serve as support during existing complaints of diarrhoea. Due to the retrospective, uncontrolled nature of this study, we were unable to accurately assess preventive efficacy as no control intervention was used and medical history was not recorded. The intervention period of 7 days could also be too small to capture all effects in this group. Regardless, the Ecologic AAD group (for antibiotic usage) did show a significant improvement on perceived QoL and reported frequency and burden of GIT symptoms following the 7-day supplementation period. The number of days with diarrhoea also appeared to be lowered from descriptive summaries but this needs to be further substantiated in follow-up studies.

Building upon the feedback of probiotic users, the present study demonstrates the importance of engaging end-users to discover unmet needs, define relevant health benefits and identify key considerations for successful implementation in daily practice. This systematic analysis of user experiences is essential to increase the external validity of studies evaluating the clinical effects of probiotics and contributes to the societal impact of probiotics in general.

\section{Limitations and directions for future studies}

Although the results of this study are promising and reinforce the health potential of probiotic supplementation, the design also presents several limitations which warrant cautious interpretation. Here we discuss the methodological limitations of this study and provide guidance for collecting user experiences in the future.

The present study aimed to review individual user experiences and therefore has different research characteristics than, for example, a RCT. Consequently, this retrospective study was not randomized and did not record concomitant medications, socioeconomic demographics, and medical history. The latter may have provided valuable insights in confounding variables that otherwise could have been used as covariates for the statistical analyses. Due to the lack of control intervention in the design of this study, results are also prone to bias from placebo-effects (Moerman, 2002), which increases the chance of Type 1 errors. Moreover, the present design does not allow to control for the potential increase in awareness of probiotic users on their symptoms and complaints throughout the study (thereby potentially altering their responses over time).

Moreover, while we compared baseline outcomes with after-use values for the burden and QoL assessments, the comparison for stool consistency and defecation frequency (i.e. diarrhoea and constipation evaluation) were made between week 1 and week 2 of probiotic consumption (as the database did not allow for other comparisons). It is therefore likely that certain beneficial effects of probiotics were already present in week 1 , thereby introducing an additional degree of uncertainty on the magnitude of the observed effects following supplementation.

Additional bias may be introduced due to the voluntary nature of this study and the fact that products were provided free of charge. It is reported, for instance, that product pricing in scientific research may affect the perceived efficacy of these interventions (Waber et al., 2008). The voluntary nature of this study also resulted in a relatively low response rate. While a higher response rate is generally preferred to reduce selection bias, a low response rate does not necessarily indicate a bias in results or study population (Curtin et al., 2000). Additionally, the ratio of males to females in this study was skewed towards females (1:4), which is to be expected, considering that women are more likely to use dietary supplements than men (Bailey et al., 2013; Beitz et al., 2002). However, earlier studies confirm that especially women with IBS are more susceptible to placebo-effects due to the strong psychological component of their complaints (Benedetti, 2014; Kim and Kim, 2018). Moreover, the microbiota composition may differ between men and women (Kim et al., 2020) and may therefore also result in different clinical outcomes.

As the intervention periods for the present study were relatively short, it warrants further evaluation of the reported effects over longer periods of time, specifically regarding the abatement of adverse effects and the continuation of reported health benefits. This need is supported by the results, as $46 \%$ of the combined population indicated to be curious about the (continuation of) longterm health benefits of probiotic supplementation.

Lastly, the present study focused on components of human health that were overarching to the primary health indication for use, such as perceived QoL and general GIT symptoms, as opposed to disease specific surveys relating to the primary indication for use. The latter may have provided additional insights into the burden of disease and health potential of probiotics and is hence recommend for future studies. Furthermore, QoL and GIT symptoms were not evaluated with standardized and validated questionnaires but were developed by the producer. The QoL questions used in this study closely resemble the SF-12 QoL questionnaire (Jenkinson and Layte, 1997), but are not identically structured, making it difficult to compare our results with previous studies. Nonetheless, the outcomes of this study provide valuable insights into the individual components that are an integral component of human QoL. 
For future studies, we recommend adopting a set of standardised and validated questionnaires, both exploring general (or indication-unspecific) health effects such a QoL and GIT symptoms, and indication-specific assessments relating to the primary indication for use. Moreover, by adopting a longer intervention period, the consistency and continuation of reported health effects, the abatement of adverse effects, as well as potential missed effects of the present study, could be captured in more detail. Recording medical history, adverse effects and concomitant medication in a systematic manner may also provide the researchers with additional means to perform analyses on confounding variables. Furthermore, controlling for unequal gender distribution may reduce the selection bias of future studies. It is also recommended to consider whether the interventions should be provided free of charge, or whether conventional over-the-counter prices should be maintained. The latter may more closely resemble the 'real-world' implementation of probiotics and may hence reduce bias in this regard. Participants could, however, still be reimbursed for their commitment of time and effort during participation.

\section{Supplementary material}

Supplementary material can be found online at https://doi. org/10.3920/BM2020.0162.

Table S1. Subgroup analyses: gastrointestinal symptoms and quality of life.

Table S2. Questionnaire design.

Table S3. Demographics and indication for use - scale 10.

Table S4. Gastrointestinal symptoms - scale 10.

Table S5. Subgroup analyses: gastrointestinal symptoms - scale 10.

Table S6. Diarrhoea improvement following probiotic supplementation - scale 10.

Table S7. Subgroup analysis: constipation improvement following probiotic supplementation - scale 10.

Table S8. Constipation improvement following probiotic supplementation - scale 10 .

Table S9. Subgroup analysis: diarrhoea improvement following probiotic supplementation - scale 10 .

Table S10. Likelihood of continued probiotic consumption - scale 5.
Table S11. Likelihood of recommending probiotics scale 5 .

Table S12. Likelihood of continued probiotic consumption - scale 10.

Table S13. Likelihood of recommending probiotics scale 10.

Figure S1. Perceived effectiveness of probiotics - scale 5 and 10.

\section{Conflict of interest}

Flach is consultant on probiotics and prebiotics at CR2O $\mathrm{BV}$ and director of clinical affairs at the Triall Foundation. Claassen is a consultant on probiotics to many parties, none of which conflict with this study. Schellinger-de Goede is Manager Healthcare at Winclove Probiotics. Besseling-van der Vaart is Head of Patient-centered Clinical Development at Winclove Probiotics. Van de Burgwal is consultant on strategic financing in life sciences at FFUND BV and director of finance at the Triall Foundation.

\section{Acknowledgements}

The analyses of results were performed by CR2O BV and NoyMed Inc, two independent contract research organizations. Access to the database of user experiences was provided by Winclove Probiotics. This work was financially supported by Winclove Probiotics.

\section{References}

Agamennone, V., Krul, C.A., Rijkers, G. and Kort, R., 2018. A practical guide for probiotics applied to the case of antibiotic-associated diarrhea in the Netherlands. BMC Gastroenterology 18: 103.

Amarenco, G., 2014. Bristol stool chart: prospective and monocentric study of 'stools introspection' in healthy subjects. Progres en Urologie 24: 708-713.

Bailey, R., Gahche, J., Miler, P., Thomas, P. and Dwyer, J., 2013. Why US adults use dietary supplements. JAMA Internal Medicine 173: 355. https://doi.org/10.1001/jamainternmed.2013.2299

Beitz, R., Mensink, G., Fischer, B. and Thamm, M., 2002. Vitaminsdietary intake and intake from dietary supplements in Germany. European Journal of Clinical Nutrition 56: 539-545. https://doi. org/10.1038/sj.ejcn.1601346

Bekkali, N., Bongers, M., Van den Berg, M., Liem, O. and Benninga, M., 2007. The role of a probiotics mixture in the treatment of childhood constipation: a pilot study. Nutrition Journal 6: 17. https://doi. org/10.1186/1475-2891-6-17

Benedetti, F., 2014. Placebo effects. Oxford University Press, Cary, NC, USA. 
Chumpitazi, B.P., Self, M.M., Czyzewski, D.I., Cejka, S., Swank, P.R. and Shulman, R.J., 2016. Bristol stool form scale reliability and agreement decreases when determining Rome III stool form designations. Neurogastroenterology and Motility 28(3): 443-448.

Curtin, R., Presser, S. and Singer, E., 2000. The effects of response rate changes on the index of consumer sentiment. Public Opinion Quarterly 64(4): 413-428. https://doi.org/10.1086/318638

De Milliano, I., Tabbers, M., Van der Post, J. and Benninga, M., 2012. Is a multispecies probiotic mixture effective in constipation during pregnancy? 'A pilot study'. Nutrition Journal 11(1): 80. https://doi. org/10.1186/1475-2891-11-80

De Vos, W.M. and De Vos, E.A., 2012. Role of the intestinal microbiome in health and disease: from correlation to causation. Nutrition Reviews 70: S45-S56.

Dimidi, E., Christodoulides, S., Fragkos, K.C., Scott, S.M. and Whelan, K., 2014. The effect of probiotics on functional constipation in adults: a systematic review and meta-analysis of randomized controlled trials. The American Journal of Clinical Nutrition 100(4): 1075-1084.

European Commission (EC), 2016. EU Regulation (EU) 2016/679 of the European Parliament and of the Council of 27 April 2016 on the protection of natural persons with regard to the processing of personal data and on the free movement of such data, and repealing Directive 95/46/EC. Official Journal of the European Union 119: 1-88.

Flach, J., 2020. Critical challenges and opportunities for probiotic innovators: advancing research and development on live microorganisms for the promotion of human health. PhD-thesis, VU Amsterdam, Amsterdam, the Netherlands.

Flach, J., Dias, A.S.M., Rademaker, S.H.M., Van der Waal, M.B., Claassen, E. and Larsen, O.F.A., 2017. Medical doctors' perceptions on probiotics: lack of efficacy data hampers innovation. PharmaNutrition 5: 103-108.

Flach, J., Koks, M., Van der Waal, M.B., Claassen, E. and Larsen, O.F.A., 2018. Economic potential of probiotic supplementation in institutionalized elderly with chronic constipation. PharmaNutrition 6: 198-206.

Grossenbacher, F., Gashi, A. and Van der Vaart, I., 2016. Use of the multispecies probiotic Winclove 500/BactoSan pro FOS leads to less gastrointestinal complaints in adults - an observational in vivo pilot study. Advances in Microbiology 6: 975-985. https://doi. org/10.4236/aim.2016.614092

Hell, M., Bernhofer, C., Stalzer, P., Kern, J. and Claassen, E., 2013. Probiotics in Clostridium difficile infection: reviewing the need for a multistrain probiotic. Beneficial Microbes 4: 39-51. https://doi. org/10.3920/bm2012.0049

Hemert, S., Verwer, J. and Schütz, B., 2013. Clinical studies evaluating effects of probiotics on parameters of intestinal barrier function. Advances in Microbiology 3: 212-221. https://doi.org/10.4236/ aim.2013.32032

Hill, C., Guarner, F., Reid, G., Gibson, G.R., Merenstein, D.J., Pot, B. and Calder, P.C., 2014. The International Scientific Association for Probiotics and Prebiotics consensus statement on the scope and appropriate use of the term probiotic. Nature Reviews Gastroenterology and Hepatology 11: 506-514.
Jenkinson, C. and Layte, R., 1997. Development and testing of the UK SF-12. Journal of Health Services Research and Policy 2: 14-18.

Kim, Y. and Kim, N., 2018. Sex-gender differences in irritable bowel syndrome. Journal of Neurogastroenterology and Motility 24: 544558. https://doi.org/10.5056/jnm18082

Kim, Y.S., Unno, T., Kim, B.Y. and Park, M.S., 2020. Sex differences in gut microbiota. World Journal of Men's Health 38: 48-60.

Kligler, B. and Cohrssen, A., 2008. Probiotics. American Family Physician 78: 1073-1078.

Koning, C., Jonkers, D., Stobberingh, E., Mulder, L., Rombouts, F. and Stockbrügger, R., 2008. The effect of a multispecies probiotic on the intestinal microbiota and bowel movements in healthy volunteers taking the antibiotic amoxycillin. American Journal of Gastroenterology 103: 178-189. https://doi.org/10.1111/j.15720241.2007.01547.x

Koning, C.J.A., 2010. Multispecies probiotics and antibiotic-associated side effects: pathophysiological and clinical evidence. $\mathrm{PhD}$-thesis, Maastricht University, Maastricht, the Netherlands.

Korterink, J.J., Ockeloen, L., Benninga, M.A., Tabbers, M.M., Hilbink, M. and Deckers-Kocken, J.M., 2014. Probiotics for childhood functional gastrointestinal disorders: a systematic review and metaanalysis. Acta Paediatrica 103: 365-372.

Lang, F.C., 2010. Use of a multi-species probiotic. Nutrafoods 9: 27-31.

Ley, R.E., Turnbaugh, P.J., Klein, S. and Gordon, J.I., 2006. Microbial ecology: human gut microbes associated with obesity. Nature 444: 1022.

Lorenzo-Zúñiga, V., Llop, E., Suárez, C., Álvarez, B., Abreu, L., Espadaler, J. and Serra, J., 2014. I.31, a new combination of probiotics, improves irritable bowel syndrome-related quality of life. World Journal of Gastroenterology 20: 8709.

Lutgendorff, F., 2009. Defending the barrier: effects of probiotics on endogenous defense mechanisms. Dissertation, Utrecht University, Utrecht, the Netherlands.

Maeda, H., 2015. Response option configuration of online administered Likert scales. International Journal of Social Research Methodology 18: 15-26.

MarketsandMarkets, 2020. Probiotics by market application. MarketsandMarkets Inc., Northbrook, IL, USA. Available at: https:// tinyurl.com/4sckdo3t

Moerman, D.E., 2002. Meaning, medicine, and the 'placebo effect'. Cambridge University Press, Cambridge, UK.

Mulder, L., 2008. A multispecies probiotic food supplement (Ecologic 825) for IBD. NUTRAfoods 7: 89-91.

Odamaki, T., Kato, K., Sugahara, H., Hashikura, N., Takahashi, S., Xiao, J.Z. and Osawa, R., 2016. Age-related changes in gut microbiota composition from newborn to centenarian: a cross-sectional study. BMC Microbiology 16: 1-12.

Persborn, M., Gerritsen, J., Wallon, C., Carlsson, A., Akkermans, L. and Söderholm, J., 2013. The effects of probiotics on barrier function and mucosal pouch microbiota during maintenance treatment for severe pouchitis in patients with ulcerative colitis. Alimentary Pharmacology and Therapeutics 38: 772-783. https:// doi.org/10.1111/apt.12451

Rangan, V., 2019. Taking a load off diagnosing constipation: utility of the plain film. Digestive Diseases and Sciences 64: 3369-3371. 
Rinninella, E., Raoul, P., Cintoni, M., Franceschi, F., Miggiano, G.A.D., Gasbarrini, A. and Mele, M.C., 2019. What is the healthy gut microbiota composition? A changing ecosystem across age, environment, diet, and diseases. Microorganisms 7: 14.

Sánchez, B., Delgado, S., Blanco-Míguez, A., Lourenço, A., Gueimonde, M. and Margolles, A., 2017. Probiotics, gut microbiota, and their influence on host health and disease. Molecular Nutrition and Food Research 61: 1600240.

Sanders, M.E., Heimbach, J.T., Pot, B., Tancredi, D.J., Lenoir-Wijnkoop, I., Lähteenmäki-Uutela, A., Gueimonde, M. and Bañares, S., 2011. Health claims substantiation for probiotic and prebiotic products. Gut Microbes 2: 1278-133.

Schork, N.J., 2015. Personalized medicine: time for one-person trials. Nature 520: 609-611.

Simren, M., Palsson, O.S. and Whitehead, W.E., 2017. Update on Rome IV criteria for colorectal disorders: implications for clinical practice. Current Gastroenterology Reports 19: 15.

Van de Burgwal, L.H.M., Van der Waal, M.B. and Claassen, E., 2018. Accelerating microbiota product development: the Societal Impact Value Cycle as a conceptual model to shape and improve publicprivate valorization processes. PharmaNutrition 6: 157-168.

Van den Nieuwboer, M. and Claassen, E., 2019. Dealing with the remaining controversies of probiotic safety. Beneficial Microbes 10: 605-616.

Van den Nieuwboer, M., Brummer, R.J., Guarner, F., Morelli, L., Cabana, M. and Claassen, E., 2015a. Safety of probiotics and synbiotics in children under 18 years of age. Beneficial Microbes 6: 615-630.

Van den Nieuwboer, M., Brummer, R.J., Guarner, F., Morelli, L., Cabana, M. and Claassen, E., 2015b. The administration of probiotics and synbiotics in immune compromised adults: is it safe? Beneficial Microbes 6: 3-17.
Van den Nieuwboer, M., Claassen, E., Morelli, L., Guarner, F. and Brummer, R.J., 2014. Probiotic and synbiotic safety in infants under two years of age. Beneficial Microbes 5: 45-60.

Van den Nieuwboer, M., Van de Burgwal, L. and Claassen, E., 2016. A quantitative key-opinion-leader analysis of innovation barriers in probiotic research and development: Valorisation and improving the tech transfer cycle. Pharmanutrition 4: 9-18. https://doi. org/10.1016/j.phanu.2015.09.003

Van der Geest, A.M., Flach, J., Claassen, E., Sijlmans, A.W., Van de Burgwal, L.H.M. and Larsen, O.F.A., 2020. European general practitioners perceptions on probiotics: results of a multinational survey. PharmaNutrition 11: 100178.

Van der Waal, M.B., Flach, J., Browne, P.D., Besseling-Van der Vaart, I., Claassen, E. and Van de Burgwal, L.H., 2019. Probiotics for improving quality of life in ulcerative colitis: exploring the patient perspective. PharmaNutrition 7: 100139.

Van Wietmarschen, H.A., Busch, M., Van Oostveen, A., Pot, G. and Jong, M.C., 2020. Probiotics use for antibiotic-associated diarrhea: a pragmatic participatory evaluation in nursing homes. BMC Gastroenterology 20: 1-9.

Venkataraman, R., Jose, P. and Jose, J., 2019. Impact of probiotics on health-related quality of life in Type II diabetes mellitus: a randomized single-blind, placebo-controlled study. Journal of Natural Science, Biology and Medicine 10: 2.

Waber, R.L., Shiv, B., Carmon, Z. and Ariely, D., 2008. Commercial features of placebo and therapeutic. Jama 299: 1016-1017.

World Health Organization (WHO), 2020. Diarrhoea. WHO, Geneva, Switzerland. Available at: https://www.who.int/topics/diarrhoea/en/ Yatsunenko, T., Rey, F.E., Manary, M.J., Trehan, I., Dominguez-Bello, M.G., Contreras, M. and Health, A.C., 2012. Human gut microbiome viewed across age and geography. Nature 468: 222-227. 